\title{
El pluriempleo en profesionales universitarios
}

\section{Miguel Escurra}

Universidad de Lima

Lima, Perú

El propósito de la investigación es aproximarse al fenómeno del pluriempleo en profesionales universitarios, tratando de conocer sus características psicológicas, consecuencias en el comportamiento, desempeño y satisfacción laboral. Para ello se desarrolló un estudio exploratorio en una muestra de 100 sujetos, 50 de los cuales eran pluriempleados y 50 con empleo único. Los resultados alcanzados indican que los grupos se diferencian en algunos aspectos relacionados con el estrés, el patrón de conducta tipo A, la apreciación del estrés laboral, la solución y afrontamiento de problemas.

pluriempleo / afrontamiento / cinco factores de personalidad / satisfacción laboral

\section{Multi-employment in college graduates}

The purpose of this paper is to study multi-employment among professionals with university degrees to understand their psychological characteristics, how it affects their performance behavior and job satisfaction. An exploratory study was developed using a sample of 100 individuals, 50 of them were multi-employed and 50 had a single job. The results indicate that sample groups show different degrees of stress, different kind of A behavior, different perception of labor stress, and different forms of coping with problems and their solution.

\section{multi-employment / coping / five personality factors / job satisfaction}


El empleo, desde un punto de vista psicológico, es un tema muy importante debido a que constituye un tipo específico de actividad humana, que es desarrollada en determinadas situaciones y contextos socioeconómicos (Blanch, 1997). El desarrollo teórico alcanzado en este campo ha permitido diferenciar las funciones que cumple, entre las que destacan: a) el aspecto económico, en la medida en que es una vía de acceso al circuito de la producción, distribución y consumo de bienes y servicios necesarios para la supervivencia; b) el aspecto sociopolítico, como medio de integración de la ciudadanía en la vida social y política; y c) el aspecto psicosocial, debido a que constituye un instrumento para el logro de autonomía financiera, social, ideológica y moral, que puede permitir la organización del tiempo cotidiano, la organización de la actividad personal y familiar y otros aspectos asociados con el desarrollo personal y la adaptación social.

El análisis del empleo profesional, en el contexto de nuestra realidad, nos permite indicar que en las estadísticas de 1997 (Webb y Fernández, 1998), la población urbana económicamente activa con profesión universitaria en total corresponde al $8,8 \%$, en tanto que en lo concerniente a los profesionales de la salud, se observa que éstos constituyen el $1,0 \%$ de la PEA, siendo los varones el $0,6 \%$ y las mujeres el $1,8 \%$.

Lo interesante de estas estadísticas es dar por sentado que los profesionales universitarios presentan una ocupación principal y probablemente una ocupación secundaria, pero la realidad nos indica que las necesidades generadas por la vida moderna y las actuales condiciones socioeconómicas que atraviesa nuestro país, han influido para que muchos profesionales se sientan "obligados" a realizar múltiples actividades con el propósito de obtener mayores ingresos económicos y alcanzar mejores niveles de ingreso. Esta situación ha generado el desarrollo del "pluriempleo" que implica un mayor esfuerzo físico y diversificación del entorno laboral, generándose probablemente por ello consecuencias psicológicas particulares pues el individuo se ve presionado a emplear mayor tiempo diario de trabajo, adoptar diferentes roles y someterse a situaciones múltiples que podrían provocar diferentes respuestas adaptativas para enfrentar la tensión generada por los cambios mencionados; todo ello, asociado a las características personales, puede llegar a producir consecuencias importantes en el comportamiento en general, así como en el desempeño y la satisfacción laboral.

Con respecto a la temática del pluriempleo Golblaum (1998), en su revisión sobre los estilos de vida y modernidad, concluyó que en la actualidad el tener múltiples empleos constituye una de las estrategias más usadas por los trabajadores para equilibrar su presupuesto. En tanto que el informe de la OIT (1998) sobre la medición de los in- 
gresos procedentes del empleo, concluye que tanto en los países industrializados como en los países en desarrollo, las economías urbanas y los mercados del trabajo, en particular, han experimentado importantes cambios estructurales. Entre estos cambios, se observa que el empleo regular asalariado ya no es tan frecuente y estable como antes, y muchos trabajadores han tenido que recurrir a otros tipos de actividades remuneradas, tales como el empleo asalariado ocasional o temporal, el empleo independiente a tiempo completo o a tiempo parcial, y sobre todo al pluriempleo.

Ante la situación antes expuesta, es necesario señalar que la revisión bibliográfica nos ha indicado una marcada ausencia de trabajos de investigación psicológica sobre el tema, tanto a nivel internacional como en nuestro medio, lo cual ha llevado a desarrollar la presente investigación exploratoria tratando de establecer las características psicológicas, las consecuencias comportamentales, el desempeño laboral y la satisfacción laboral de los profesionales pluriempleados.

\section{Patrón de conducta tipo A}

El patrón de conducta tipo A, fue propuesto por Friedman y Rosenmam (1959) y constituye un complejo de emociones y de acciones que suponen: a) disposiciones comportamentales como ambición, agresividad, competitividad e impaciencia; b) conductas espe- cíficas tales como tensión muscular, estilo rápido y enfático de hablar, ritmo acelerado de actividades; c) respuestas emocionales tales como irritabilidad, hostilidad (en muchos casos provocadas por impaciencia) y cólera (León, Romero y Sirlopú, 1995).

Este constructo se asume relevante en la medida en que existen investigaciones cuyos hallazgos apuntan a demostrar que los sujetos con patrones de conducta tipo A en situaciones de estrés presentan más pulsaciones y presión sistólica y diastólica que los tipo B (Pittner et al., 1983), y además que su presencia constituye, con otros aspectos, un factor de riesgo para el desarrollo de enfermedades coronarias (Loret de Mola, 1987; León y Sirlopú, 1996; Borges et al., 1997; Hernández, 1997). Estudios más recientes parecen indicar que el patrón de conducta tipo A no constituye un todo monolítico, sino que estaría formado por diversos factores que contribuyen de forma diferencial al desarrollo de patología coronaria (Borges et al., 1997).

Entre las características más saltantes tipificadas para los individuos con patrón de conducta tipo A, encontramos que por lo general se reporta que es un trabajador incansable, comprometido con su trabajo, ambicioso, siempre escaso de tiempo debido a las múltiples actividades que desempeña, lo cual podría aproximarse a quienes tienen empleos múltiples. 


\section{TEORÍA DE LOS CINCO GRANDES \\ FACTORES DE LA PERSONALIDAD}

La personalidad ha sido descrita como un conjunto de componentes que conforman un sistema (Laak, 1996), el cual al tratar de ser estudiado ha llevado al desarrollo de diferentes teorías, motivo por el cual hasta ahora ninguna de ellas ha logrado predominar sobre las demás.

En la actualidad se aprecia que no existe un lenguaje común para la evaluación de la personalidad, pues aun entre los teóricos de la personalidad que asumen un mismo planteamiento metodológico como es el factorial, en lo que respecta al número de los factores que deben ser tomados en cuenta, varían notablemente; así, por ejemplo, Cattell, Eysenck, Guilford y Comrey han desarrollado sistemas de organización de los rasgos de personalidad no reducibles entre sí y a menudo incompatibles (Colom, 1995),

El modelo de los cinco grandes factores (Big Factor) propone cinco dimensiones fundamentales para la descripción y la evaluación de la personalidad que se sitúan en un nivel de generalidad intermedio con respecto a los modelos que defienden pocas dimensiones extremadamente generales como es el caso de Eysenck, y respecto de los modelos que prevén un mayor número de dimensiones de capacidad más específica, pero de menor generalidad, como es el caso de los dieciséis factores de Cattell, los trece factores de Guilford y los ocho de Comrey. En este modelo convergen dos tradiciones de investigación diferentes que se han entrelazado en el transcurso de los años: la lexicográfica y la factorialista (Colom, 1995).

La tradición lexicográfica, que se basa en la hipótesis de la concepción lingüística de Cattell (1943, en Caprara, Barbaranelli y Borgogni, 1995), considera que las diferencias individuales más saltantes y socialmente relevantes están codificadas en el lenguaje cotidiano. El análisis de este lenguaje cotidiano ha sido considerado como la fuente principal de todos los posibles descriptores de la personalidad, lo que ha llevado a la construcción de distintos listados de términos, sobre todo adjetivos, diseñados para el examen de las diferencias individuales. El examen de las relaciones entre los diferentes descriptores de la personalidad ha evidenciado repetidamente la presencia de cinco grandes factores, independientemente de las técnicas de factorización, de la naturaleza y de los procedimientos de evaluación (auto y heteroevaluación), de las características (sexo/edad) de las poblaciones y de los contextos lingüísticos y culturales (Estados Unidos, Alemania, Holanda, Italia, Japón, Filipinas, Taiwan [Caprara, Barbaranelli y Borgogni, 1995]). De manera que el empleo de esta estrategia ha permitido identificar en dichos factores las dimensiones de personalidad aisladas 
en el ámbito de la tradición factorialista, por autores como Cattell, Guilford, Eysenck y Comrey mediante cuestionarios de personalidad como el 16PF, el Guilford-Zimmerman (GZTS), el EPQ, el CPS.

Los cinco grandes factores de la personalidad son los siguientes:

- Energía (E). Es el factor que hace referencia a los aspectos asociados a los constructos: extraversión o surgencia. Se ha denominado como energía debido a los significados que suelen asociarse a estas características, en las otras denominaciones, en nuestro contexto lingüístico.

- Afabilidad (A). Hace referencia a la dimensión comúnmente identificada como agrado o cordialidad en contraposición con hostilidad.

- Tesón (T). Hace referencia a la capacidad de autorregulación o autocontrol, tanto por lo que concierne a los aspectos inhibitorios, como a los aspectos proactivos

- Estabilidad emocional (EE). Se refiere a las características que remiten esencialmente a lo opuesto del afecto negativo.

- Apertura mental (AM). Hace referencia a la dimensión que otros autores han definido como cultura y apertura a la experiencia, y presta particular atención a las características que se asocian a estas diferentes denominaciones, en nuestro contexto lingüístico.
Los cinco grandes factores de la personalidad constituyen en la actualidad un intento de mediación y unificación entre los distintos puntos de vista existentes con respecto a la personalidad (Colom, 1995), por lo cual se consideró pertinente su estudio, en la medida en que puede permitir identificar el perfil de personalidad que presenta el profesional pluriempleado.

\section{ESTRÉS LABORAL}

El estrés laboral es definido como el desequilibrio percibido entre las demandas profesionales y la capacidad de la persona para llevarlas a cabo (Slipak, 1996). Ha sido este concepto de subjetividad individual o de percepción de acuerdo con la personalidad, lo que ha generado las mayores discusiones entre los teóricos, en lo que se refiere a las repercusiones jurídico-laborales del estrés como enfermedad profesional o laboral.

No todos reaccionan de la misma forma; por ejemplo, si la exigencia es adecuada para la capacidad, conocimiento y estado de salud de la persona, el estrés tenderá a disminuir y podrá tener signos positivos, estimulantes, que le permitirán progresar en el ámbito de trabajo y obtener mayor proyección en éste con gratificación personal, espiritual y material. Por el contrario, un desbalance entre la demanda y la adaptación puede generar un mayor distrés de forma crónica que puede llegar a ser invalidante. Así, una valoración cuanti- 
tativa del volumen del trabajo individual podría generar un estrés agradable y motivador o un estrés debilitante de las capacidades y valoraciones personales, como así también su ausencia, el desempleo o la jubilación puede provocar un grado extremo de distrés.

Uno de los mecanismos de respuesta, previa valoración de un estresor, es la lucha o la huida. Si estas situaciones de estrés se dan en el plano laboral (como la inseguridad, la competencia, la búsqueda de eficacia), nos encontramos con que no podemos luchar con el gasto energético correspondiente ni tampoco, teóricamente, responder con la huida, es decir escapar del distrés. Está claro que la huida en el ámbito laboral es el ausentismo, que junto con las enfermedades laborales pueden ser considerados como índices de la repercusión del estrés organizacional sobre los trabajadores.

La actividad laboral es generadora de estrés y es justamente por la conveniencia de mantener el puesto de trabajo que esa lucha es hoy más intelectual y psicológica que física, por lo que en ella no se consume la energía resultante (distrés).

Con respecto al estrés laboral, se ha intentado estudiar con diferentes modelos, tomando diferentes factores etiológicos. Así, McLean hace referencia al contexto, a la vulnerabilidad y al factor estresante, que al concurrir o superponerse generarán un grado mayor de estrés. Otros como Pearson y su modelo de ajuste ambiental, otorgan una importancia mayor a las percepciones objetivas y/o subjetivas del yo y el ambiente. En tanto que Baker plantea su modelo sobre el ambiente de trabajo y hasta qué grado permite a las personas modificar las respuestas al estrés. El concepto de modelo de control de decisiones de trabajo sostiene que el estrés resulta de un desequilibrio entre las exigencias impuestas a un trabajador y su capacidad para modificarlas (Slipak, 1996).

La Organización Internacional del Trabajo (1993) se refiere al estrés laboral como la enfermedad que es un peligro para las economías de los países industrializados y en vías de desarrollo, pues resiente la productividad al afectar la salud física y mental de los trabajadores. Según Kalimo (1988), múltiples estudios epidemiológicos han demostrado que la salud está relacionada con los factores psicosociales presentes en el trabajo y que la función de esos factores, tanto con respecto al estado de salud como a las causas de la enfermedad, es de alcance relativamente general, de forma que estos factores pueden contribuir a causar y agravar una enfermedad e influir en los resultados de las medidas de curación y rehabilitación. Las personas que se encuentran sometidas a estrés tienden a abandonar el empleo como respuesta de huida, lo que determina un alto índice de rotación de personal en las empresas. Las personas sufren cuando se sienten su- 
peradas por las demandas laborales exigentes, pero también cuando no tienen empleo o se angustian pensando que pueden llegar a ser un desocupado más.

El estrés laboral puede ser clasificado de dos formas: a) episódico, es el generado por un evento casual como un despido, por ejemplo; y b) crónico, que se presenta cuando la persona se encuentra sometida a situaciones constantes.

La bibliografía reporta la existencia de estresores extraorganizacionales (Ivanicevich y Matteson, 1992, Slipak, 1996), que se plantean fuera del ámbito de la empresa, y comprenden los factores familiares, políticos, sociales y económicos que inciden sobre el individuo. Estudios recientes sugieren una mayor incidencia de los factores estresantes laborales sobre la vida familiar y conyugal, así como una mayor interacción entre el ámbito laboral y el hogar o la vida de relación social, pues la inadecuada interconexión entre el hogar y el trabajo puede generar conflictos psicológicos y fatiga mental, falta de motivación y disminución de la productividad, como así también un deterioro de la relación conyugal y familiar. También es necesario observar que las particularidades y los períodos de la historia de un país, su situación económica y social, inciden en forma directa sobre el individuo, de tal manera que es factible apreciar, en casos extremos, un aumento de enfermedades psicosomáticas ante las crisis económicas y un incremento de los conflictos familiares y sociales.

Los problemas o estresores organizacionales, que se presentan dentro del ámbito laboral inciden en la vida personal del sujeto provocando dificultades hogareñas las que, al aumentar, se pueden potenciar causando un estrés posterior que se llevará nuevamente al ámbito laboral y generará así dificultades en el rendimiento de sus funciones, produciéndose un círculo vicioso de retroalimentación mutua.

Otro tipo de estresores son los intraorganizacionales, que se plantean dentro del ámbito de la empresa y pueden clasificarse en los siguientes tipos:

- Estresores del ambiente físico. Conformados por los siguientes aspectos:

- Ambiente laboral inadecuado. Son los estresores del ambiente físico y pueden ser: falta de luz o luz muy brillante; ruido excesivo o intermitente; vibraciones; aire contaminado; alta o baja temperatura. Estos factores requieren de una doble adaptación, tanto física como psicológica.

- Sobrecarga de trabajo. Es el estrés originado por sobreestimulación, se presenta por exigencias psicosensoriales violentas, simultáneas, numerosas, persistentes y variables. Exigen una adaptación fuera del límite nor- 
mal; es frecuente que se presente en: controladores de tráfico aéreo; obreros en cadena rápida y compleja; trabajadores sometidos a cambios continuos y abundancia de información; víctimas de catástrofes; emigrados; digitadores de información a sistemas de computación. Este tipo de estrés puede generar: tensión nerviosa, fatiga, irritabilidad, crisis de decisión, ansiedad, confusión, embotamiento, desconcentración.

- Alteración de ritmos biológicos. Se produce al alterarse las constantes biológicas determinadas por el ritmo circadiano, el cual está determinado a su vez por las secreciones hormonales, los ciclos del sueño y el ritmo metabólico. Se requiere de un alto esfuerzo adaptativo, lo que puede generar irritabilidad, disminución de la concentración, trastornos del sueño, fatiga, ansiedad, además de provocar modificaciones en la vida social, conyugal y sexual. Por lo general se presenta en: trabajadores nocturnos; pilotos de líneas aéreas y azafatas; controladores de tráfico aéreo, personal de sanidad; personal de seguridad; trabajadores del transporte; diplomáticos; atletas profesionales.

- Responsabilidades y decisiones muy importantes. Es el estrés del personal jerárquico o con grados de responsabilidad; se debe a: responsabilidades numerosas $\mathrm{y}$ variables; trabajo intelectual excesivo; tensión psicológica continua; inseguridad laboral; competencia; búsqueda de la eficacia; marcha contra reloj; adaptación a situaciones nuevas y datos inestables. Es frecuente que en quienes lo padecen se acumulen factores de riesgo e inadecuación familiar y social por falta de tiempo y agotamiento físico. Este tipo de estrés genera agotamiento, fatiga, manifestaciones psicosomáticas, trastornos del sueño, disminución del deseo sexual, impaciencia, pérdida de la iniciativa, dificultad en la toma de decisiones, adicciones.

- Estimulación lenta y monótona. Es el estrés por subestimulación, se produce por la falta de estímulo normal y fisiológico de los sentidos y del pensamiento, se presenta, por ejemplo, en el trabajo rutinario y automatizado que no permite la creatividad y el pensamiento independiente, en casos como los siguientes: cadena de trabajo lenta y monótona; jubilación brusca; vacaciones excesivamente tranquilas, $y$ puede llegar a generar distracción, falta de atención y aumento de los accidentes de trabajo. 
- Condiciones laborales inadecuadas. Es la causa de estrés en los obreros no calificados, que comprenden: malas condiciones de trabajo; salarios bajos; alimentación inadecuada e insuficiente; ausencia de perspectivas de progreso; pocas posibilidades de recreación; inestabilidad laboral por renovación tecnológica; disposición de las líneas de montaje.

- Estresores de nivel individual. Incluye los siguientes aspectos:

- Sobrecarga de trabajo. Es el estrés por sobreestimulación, la cual puede ser objetiva o subjetiva, de acuerdo con la valoración y las características de las personas. Se considera sobrecarga de trabajo el ejercer responsabilidades importantes, por ejemplo, responsabilidad por la tarea o las decisiones de otros. Las personas que habitualmente tienen más estrés fuman más, tienen presión arterial más alta y tienen aumentados los índices de colesterol en relación con aquéllas que solamente se responsabilizan por objetos o por la realización de su propia tarea. La sobrecarga puede generar insatisfacción, tensión, disminución de la autoestima, sensación de amenaza, taquicardia, aumento del colesterol, del consumo de nicotina y otras adicciones, para tratar de responder a la sobreexigencia. Desde el punto de vista laboral, puede llegar a provocar la disminución de la motivación en el trabajo, de los aportes o sugerencias laborales y de la calidad de las decisiones, el aumento del índice de accidentes laborales, el deterioro de las relaciones interpersonales y el aumento del ausentismo.

- Conflicto de roles. Puede ser objetivo o subjetivo. Será un conflicto de roles objetivo cuando existen dos o más personas dando órdenes contradictorias. En cambio, un conflicto de roles subjetivo se produce como resultado de la contradicción entre las órdenes formales que recibe el individuo y los propios valores y metas del sujeto. Los conflictos de roles generan gran ansiedad e insatisfacción por el trabajo, mayor aun cuanto más autoridad ostenta el que expresa las órdenes contradictorias. Estas situaciones tienden a disminuir la creatividad de los individuos sometidos al conflicto, ya que el temor a fallar provoca un desempeño laboral menos satisfactorio. En el aspecto personal, el individuo suele tener hipertensión arterial y aumento del colesterol.

- Ambigüedad de roles. Se refiere a la falta de claridad sobre el papel que se está desempeñando, 
los objetivos del trabajo individual o el alcance de las responsabilidades. Se produce estrés, depresión y deseos de abandonar el puesto de trabajo cuando esta situación se mantiene en el tiempo en forma crónica. Es característica de este caso la disminución de la autoestima ante la falta de satisfacción por la tarea que se ejerce. Información y comunicación adecuadas disminuyen este tipo de conflictos, al mejorar la orientación de las tareas laborales.

- Discrepancias con las metas de la carrera laboral. Las que se dan por la falta de seguridad laboral, las dudas sobre los ascensos y las legítimas ambiciones frustradas. La insatisfacción en cuanto a las discrepancias entre aspiraciones y logros lleva a la ansiedad y a la frustración, a la depresión y al estrés, especialmente entre los 40 y 50 años. Es frecuente que, además de una calidad deficiente del rendimiento laboral, encontremos adicciones como el alcohol, las drogas, el café, el tabaco, etc.

- Los estresores de nivel grupal. Incluyen aspectos tales como: a) falta de cohesión grupal; b) conflictos intragrupales; c) conflictos intergrupales; d) apoyo inadecuado del grupo.

Un grupo está formado por dos o más personas que comparten valo- res, metas, normas y que se interrelacionan entre sí. Una organización puede crear un grupo de trabajo como una estructura: son los llamados grupos formales de la organización, aunque también grupos informales, que interactúan dentro y fuera de la empresa. La falta de apoyo por parte del grupo o sus miembros, como así también los conflictos inter e intragrupales, pueden, en su máxima gravedad, hacer caer una organización. En esta situación se genera un alto grado de inseguridad, ansiedad $\mathrm{y}$ ausentismo como una manera de abandonar el conflicto.

Los estresores organizacionales son aquéllos que se plantean en la organización y pueden ser de las siguientes clases:

- Clima de la organización. Una organización tiene un carácter, una atmósfera particular, propia de su esquema productivo. Este clima puede condicionar la conducta de los individuos que la integran, pero su valoración es difícil de lograr, ya que su medición carece de rigor científico. Puede ser un clima tenso, relajado, cordial o no, etc. Todo ello produce distintos niveles de estrés en los individuos, según la susceptibilidad o vulnerabilidad que tenga cada uno.

- Estilos gerenciales. Que pueden estar determinados por estructuras rígidas e impersonales, por una 
supervisión o información inadecuada, por la imposibilidad de participar en las decisiones, etc.

- Tecnología. Es de un alto valor estresante la disponibilidad con que la organización dota a sus empleados de los elementos necesarios para su acción, como así también la capacitación para el uso de la tecnología respectiva. Los recursos deben ser acordes con los requerimientos y exigencias laborales.

- Diseños y características de los puestos. Permiten la motivación para el progreso dentro de la organización laboral.

- Fechas topes no racionales. Es un importante factor de estrés que se produce por establecimiento de metas inalcanzables en los tiempos prefijados para ello.

- Control de sistemas informáticos. Ocurre cuando los integrantes de la organización, objetiva o subjetivamente, no dominan o controlan los sistemas informáticos que se utilizan. Se generan situaciones de ansiedad y estrés que disminuyen la eficiencia.

\section{Afrontamiento}

El afrontamiento puede ser definido, siguiendo a Lazarus (1966), como: los esfuerzos cognitivos que se desarrollan para manejar las demandas internas o externas y los conflictos entre ellas, que son evaluadas como desbordantes o excedentes en relación con los recursos de las personas.

En un enfoque que relaciona el afrontamiento con el estrés Endler y Parker (1990) indican que los estudios realizados evidencian el rol importante que juega el afrontamiento como mediador entre los hechos antecedentes estresantes y las consecuencias que se producen como la ansiedad, depresión, malestar psicológico, quejas somáticas.

Lazarus (1996), propone que el afrontamiento afecta el proceso emocional básicamente de dos maneras:

- Focalizarse en el problema. Se presenta cuando la persona busca cambiar la relación existente, ya sea alejando o disminuyendo el impacto de la amenaza, e incluye estrategias de resolución de problemas, toma de decisiones, manejo del propio tiempo, búsqueda de consejo o elaboración de un plan.

- Focalizarse en la emoción. Ocurre cuando los esfuerzos del afrontamiento se dirigen a cambiar principalmente la manera en que se interpreta la realidad y con ello también modificar la reacción emocional. Este objetivo implica pensar más que actuar para cambiar la relación entre persona-ambiente y se logra a través de una reestructuración cognitiva. Las estrategias de afrontamiento que se ubican en este grupo también son llamadas estrategias cognitivas de afrontamiento y pueden tender a un carácter pasivo, pre- 
sentándose frecuentemente en personas que creen que es muy difícil hacer algo para cambiar el estresor y, por lo tanto, sólo se debe tratar de resistirlo.

La inclusión del afrontamiento en el estudio se sustenta en la necesidad de evaluar cómo es que los profesionales universitarios con pluriempleo se enfrentan a las situaciones estresantes que se generan en su vida diaria.

\section{DESEMPEÑO LABORAL}

El desempeño laboral es definido como la forma con que una persona ejecuta una determinada actividad laboral. La evaluación del desempeño puede ser definida como un proceso de una apreciación sistemática del comportamiento de las personas en la ejecución de una determinada actividad laboral (Chiavenato, 1996).

En general, el esfuerzo de cada individuo está en función del valor de las recompensas y de la probabilidad de que éstas dependan del esfuerzo, siendo este esfuerzo individual dirigido por un lado por las capacidades y habilidades del individuo y, por otro lado, por las percepciones que él tiene del papel que debe desempeñar (Lawler \& Porter, 1973).

Por lo general, la evaluación del desempeño es realizado en las organizaciones por diferentes motivos, siendo mayormente el jefe directo del sujeto el encargado de desarrollarla, pero la bibliografía indica que si bien la autova- loración del desempeño es usada por muy pocas organizaciones, ésta sólo puede utilizarse cuando el grupo de estudio está compuesto por personas de buen nivel cultural y un alto cociente intelectual, además de tener equilibrio emocional y una buena capacidad para hacer una autoevaluación despojada de subjetivismo y de distorsiones de índole personal y que ha tenido un relativo éxito cuando ha sido aplicado a personas de nivel universitario (Chiavenato, 1996).

\section{SATISFACCión LABORAL}

La satisfacción en el trabajo es una relación afectiva del individuo con su quehacer, determinada por innumerables variables micro y macrosociales; así, por ejemplo, la satisfacción laboral está condicionada en cierta medida por variables de la persona encuestada: edad, sexo, educación, categoría laboral, etc. Estas variables a su vez están teñidas con una connotación valorativa atribuida por la empresa, pueblo o ciudad y cultura en la cual el trabajador está inmerso y que se denominarán factores situacionales que inciden en la satisfacción laboral.

La satisfacción en el trabajo ha sido definida de muy diversas maneras y relacionada con muchas otras variables tales como rasgos de personalidad, satisfacción de necesidades, motivaciones, calidad y cantidad de producción, etc.

El concepto de satisfacción en el trabajo se hace sinónimo de moral de tra- 
bajo con acepciones muy diferentes; sin embargo, la moral laboral es un concepto más grupal que individual y existe cuando todos o casi todos los componentes de la unidad comparten un cierto grado de ilusión y entusiasmo en la consecución de un mismo objetivo. La satisfacción en el trabajo alude más bien a lo que señala Smith como: "la respuesta afectiva de los trabajadores hacia los diferentes aspectos implicados en su trabajo" (López, 1982).

Tal como lo indica López (1982), una definición más amplia y operacional establece que la satisfacción en el trabajo es la extensión en que son satisfechas las necesidades de un individuo y el grado en que este individuo percibe que su satisfacción laboral proviene de su puesto de trabajo.

Vroom (1964, en López, 1982) asumiendo un enfoque pragmático del tema indicó cinco aspectos dentro de las situaciones laborales que están relacionadas con la motivación, las cuales son: a) el salario que recibe el trabajador; b) la oportunidad de emplear su energía física y/o mental; c) la oportunidad de entrar en contacto social con otras personas; d) la obtención de estatus; y e) la oportunidad de contribuir a la producción de bienes y servicios.

La satisfacción en el trabajo no implica el conformismo o la resignación con una situación laboral dada; es más bien, por el contrario, un indicador del grado general de compromiso y responsabilidad con que el trabajador asume su tarea.

\section{MÉtodo}

\section{Participantes}

Dada la naturaleza de la investigación, se trabajó con un grupo de 100 profesionales universitarios vinculados al área de la salud (medicina, odontología y psicología), los cuales fueron divididos en dos grupos, el primero constituido por 50 profesionales que se dedicaban a una sola actividad laboral; mientras que el segundo grupo estuvo conformado por 50 profesionales que se desempeñaban en múltiples empleos, es decir que realizaban actividades relacionadas con su profesión en por lo menos dos o más centros de trabajo. Como se puede apreciar en la tabla $\mathrm{N}^{\mathrm{o}} 1$, los grupos de estudio están conformados por cantidades de profesiones similares.

Los participantes fueron obtenidos basándose en un procedimiento de muestreo no probabilístico intencional $\mathrm{y}$ fueron evaluados, generalmente, en sus centros de trabajo. Las principales características de los grupos estudiados (véase tabla $\mathrm{N}^{\mathrm{o}} 1$ ) indican que, en mayor proporción, los sujetos de empleo único tienen un menor ingreso económico y dedican menos horas semanales a realizar sus actividades laborales; en tanto que el grupo de pluriempleo, presenta un mayor ingreso en promedio y dedica más horas a sus actividades laborales. 
Tabla № 1

Características de los participantes estudiados

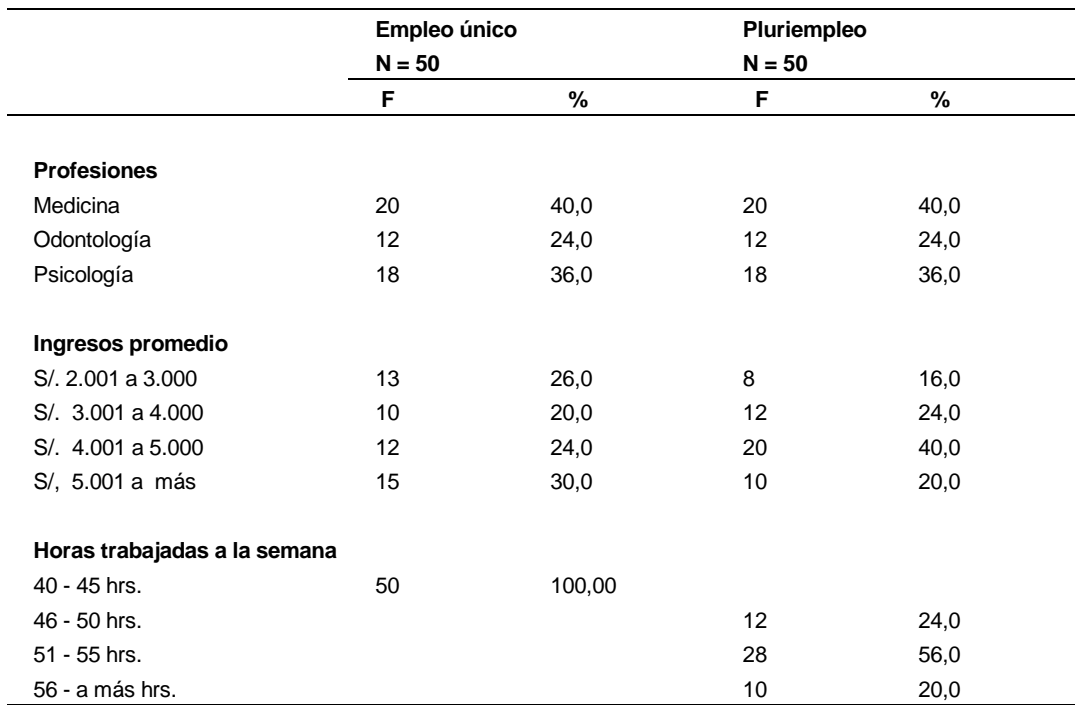

\section{Instrumentos}

En el estudio se utilizarán los siguientes instrumentos:

\section{Inventario de autorreporte de con- ducta tipo A de Blumenthal}

El instrumento está conformado en total por 28 ítems, de los cuales 21 evalúan el patrón de conducta tipo A, que es caracterizado por la alta competitividad, impaciencia, intenso compromiso con el trabajo, hostilidad y un agudo sentido de la urgencia, siendo por ello considerado por muchos autores como uno de los factores que originan transtornos coronarios. Además se incluyen siete ítems que evalúan la conducta tipo $\mathrm{B}$, que implica rasgos totalmente opuestos a la conducta tipo A.
Este inventario fue adaptado y validado por León, Romero y Sirlopú (1995), quienes trabajaron con una muestra de 1.145 estudiantes universitarios, los resultados confirmaron que la prueba presenta validez y confiabilidad. En el presente estudio fue necesario evaluar la confiabilidad, debido a que puede variar en diferentes muestras (Muñiz, 1994 y Muñiz, 1996).

Los resultados presentados en la tabla $\mathrm{N}^{\circ} 2$ permiten observar que todas las correlaciones ítem-test corregidas, asumidas como indicadores de la validez de constructo (Kline, 1993), alcanzan valores estadísticamente significativos ( $\mathrm{p}<$ $.05)$ y la confiabilidad evaluada a través del coeficiente alfa de Cronbach fue de 0.80 , resultados que corroboran la validez y confiabilidad del instrumento. 
Tabla № 2

Validez y confiabilidad del inventario de autorreporte de conducta tipo A de Blumenthal

\begin{tabular}{|c|c|c|}
\hline Item & $M$ & $r_{\text {it }}$ \\
\hline$\overline{1}$ & 4.25 & $.22^{*}$ \\
\hline 2 & 4.34 & $.23 *$ \\
\hline 3 & 4.65 & .24 * \\
\hline 4 & 4.68 & .25 * \\
\hline 5 & 5.21 & .28 * \\
\hline 6 & 5.24 & .29 * \\
\hline 7 & 4.10 & $.30 *$ \\
\hline 8 & 5.13 & .34 * \\
\hline 9 & 6.98 & .35 * \\
\hline 10 & 4.75 & .24 * \\
\hline 11 & 5.46 & .25 * \\
\hline 12 & 4.40 & $.26 *$ \\
\hline 13 & 5.41 & $.27^{*}$ \\
\hline 14 & 6.63 & .28 * \\
\hline 15 & 5.23 & $.31 *$ \\
\hline 16 & 4.14 & $.30 *$ \\
\hline 17 & 5.52 & $.36 *$ \\
\hline 18 & 4.32 & .29 * \\
\hline 19 & 5.82 & $.28 *$ \\
\hline 20 & 4.97 & .25 * \\
\hline 21 & 5.30 & $.26 *$ \\
\hline 22 & 4.34 & .24 * \\
\hline 23 & 6.64 & $.27^{*}$ \\
\hline 24 & 6.71 & $.20 *$ \\
\hline 25 & 4.42 & $.21^{*}$ \\
\hline 26 & 5.10 & .23 * \\
\hline 27 & 4.20 & .28 * \\
\hline 28 & 5.32 & .34 * \\
\hline 29 & 4.54 & $.41^{*}$ \\
\hline 30 & 5.22 & $.33 *$ \\
\hline 31 & 6.45 & $.26 *$ \\
\hline 32 & 5.84 & .28 * \\
\hline 33 & 4.89 & $.20 *$ \\
\hline 34 & 5.12 & .22 * \\
\hline 35 & 6.10 & $.28 *$ \\
\hline 36 & 5.09 & $.27^{*}$ \\
\hline 37 & 4.75 & $.35 *$ \\
\hline 38 & 5.46 & $.40 *$ \\
\hline \multicolumn{3}{|c|}{ Alfa $=0.80$ * } \\
\hline & & $\mathrm{N}=$ \\
\hline
\end{tabular}

\section{Cuestionario de afrontamiento de Carver (Cope)}

Este instrumento fue creado por Carver y Scheier (1989) en los Estados Unidos y está dirigido a evaluar los diferentes estilos de afrontamiento que las personas utilizan frente a diversas situaciones estresantes.

El cuestionario está conformado por 52 ítems con formato tipo Likert de 4 puntos de calificación, que se refieren a diferentes situaciones estresantes ante las cuales el sujeto debe responder según las siguientes alternativas:

- casi nunca hago esto

- a veces hago esto

- usualmente hago esto

- hago esto con mucha frecuencia

La escala contiene 13 subescalas que corresponden a los 13 estilos de afrontamiento propuestos por Carver et al. (1989).

- Estilos de afrontamiento que enfocan el problema, que incluye:

- Afrontamiento activo (ítems 1, 14, 27 y 40).

- Planificación (ítems 2, 15, 28 y 41).

- Supresión de actividades competentes (ítems 3, 16, 29 y 42).

- Postergación del afrontamiento (ítems 4, 17, 30 y 43).

- Búsqueda de apoyo social por razones instrumentales (ítems 5, $18,31$ y 44$)$. 
- Estilos de afrontamiento que enfocan la emoción, conformado por:

- Búsqueda de apoyo social por razones emocionales (ítems 32, 19, 6 y 45).

- Reinterpretación positiva y crecimiento (ítems 7, 20, 33 y 46).

- Aceptación (ítems 8, 21, 34 y 47).

- Negación (ítems 11,24, 37 y 50).

- Acudir a la religión (ítems 9, 22, 35 y 48).

- Otros estilos de afrontamientos propuestos, que incluyen:

- Enfocar y liberar emociones (ítems 10, 23, 36 y 49).

- Desentendimiento conductual (ítems 12, 25, 38 y 51).

- Desentendimiento mental (ítems $13,26,39$ y 52 ).

Cada una de las escalas está conformada por cuatro ítems, los que se puntúan de acuerdo a una plantilla. Los puntajes obtenidos en cada ítem se suman con los correspondientes a cada subescala, de manera que se pueden alcanzar 13 puntajes que permiten caracterizar el perfil de afrontamiento. Finalmente, es posible establecer una jerarquía que permite determinar qué estilos de afrontamiento fueron más utilizados.

El Cope tiene dos formatos, que permiten el afrontamiento situacional y el afrontamiento disposicional. El contenido de los ítems es el mismo y sólo varía el modo en que son formulados:

- Formato disposicional. Los ítems están formulados en términos de evaluar lo que la persona usualmente hace cuando se encuentra en situaciones de estrés.

- Formato situacional. Los ítems se plantean de tal manera que evalúen lo que la persona hizo en una situación específica de afrontamiento o durante un período específico de tiempo en el cual afrontaba estrés.

En el presente estudio se aplicó el Cope en su forma disposicional. Este instrumento ya ha sido utilizado en nuestro medio por Casuso (1996), quien trabajó con estudiantes universitarios, evaluándose la validez y confiabilidad del instrumento.

Debido a que la confiabilidad de una prueba puede variar de acuerdo con las características de la muestra (Martínez, 1996; Anastasi y Urbina, 1998), fue necesario calcular los coeficientes alfa de Cronbach.

Los resultados encontrados en la tabla $\mathrm{N}^{\mathrm{o}} 3$ indican que se alcanzan valores que fluctúan entre 0.54 para desentendimiento mental y 0.72 para postergación de afrontamiento. Para la evaluación de la significación estadística de los coeficientes alfa, se aplicó el procedimiento de análisis de Feldt y Kristoff (Muñiz, 1994: Muñiz, 1996), apreciándose que todas las escalas son estadísticamente significativas, lo que corrobora que el Cope es confiable. 
Tabla № 3

Confiabilidad de la prueba Cope de afrontamiento de Carver

\begin{tabular}{lcc}
\hline Subdimensiones & Coeficiente alfa & F \\
\hline Afrontamiento activo & .70 & $3.30^{*}$ \\
Planificación & .68 & $3.13^{*}$ \\
Supresión de actividades competentes & .69 & $3.23^{*}$ \\
Postergación del afrontamiento & .72 & $3.57^{*}$ \\
Búsqueda de apoyo social por razones instrumentales & .71 & $3.45^{*}$ \\
Búsqueda de apoyo social por razones emocionales & .69 & $3.23^{*}$ \\
Reinterpretación positiva y crecimiento & .68 & $3.13^{*}$ \\
Aceptación & .70 & $3.33^{*}$ \\
Acudir a la religión & .65 & $2.86^{*}$ \\
Enfocar y liberar emociones & .68 & $3.13^{*}$ \\
Negación & .69 & $3.23^{*}$ \\
Desentendimiento conductual & .63 & $2.70^{*}$ \\
Desentendimiento mental & .54 & $2.17^{*}$ \\
\hline
\end{tabular}

${ }^{*} p<.05 ; N=100$

\section{Escala de apreciación del estrés sociolaboral}

La escala de apreciación del estrés sociolaboral ha sido creada por Fernández y Mielgo (1996). Este instrumento se aplica a los adultos, desde 18 a 85 años, ya sea de forma individual o grupal. Tiene por finalidad evaluar, a partir de las situaciones que potencialmente generen estrés, la incidencia y la intensidad con que afectan la vida de cada sujeto.

Esta escala tiene como función principal estudiar el estrés en el ámbito laboral y como objetivo básico evaluar el peso de los distintos acontecimientos en la vida de los individuos, de manera que permita: a) conocer el número de acontecimientos estresantes que han estado presentes en la vida del sujeto; b) apreciar la intensidad con que cada uno vive o ha vivido esos sucesos vitales; y c) conocer si esos acontecimientos estresantes han dejado de afectarle o todavía le siguen afectando.

La escala se sustenta en los trabajos aplicados de Holmes y Rahe (1967) y Lazarus (1966), quienes expresan que a lo largo del ciclo vital se dan abundantemente actividades, desempeño de roles, vivencias de sucesos, experiencias, situaciones que desencadenan estrés, ansiedad, nerviosismo, tensión y otros síntomas en los sujetos. Pero no todos los agentes potencialmente estresantes están presentes en la vida de cada individuo ni afectan de la misma manera. Al contrario, la respuesta al estrés es diferencial y depende tanto de los agentes como de la reacción y capacidad de afrontamiento por parte del individuo. 
En términos generales, el sujeto hace una valoración cognitiva de los acontecimientos estresantes y también de sí mismo frente a ellos. Aunque el suceso puede ser relevante o vital, su respuesta puede ser adecuada si el sujeto cuenta con la estrategia de afrontamiento adecuada (estrategia de afrontamiento cognitivo, afectivo, social).

En la vivencia del estrés, es fundamental el planteamiento cognitivo (de uno y del contexto), pero también lo es el afectivo-emocional de la forma como se vive dicho suceso vital.

La escala consta de 50 enunciados distribuidos en tres ámbitos de contexto: a) trabajo en sí mismo; b) contexto laboral; y c) relación del sujeto con el trabajo. Este instrumento no ha sido trabajado en nuestro medio, por lo que fue necesario estudiar la validez y confiabilidad de la escala

Los resultados del análisis psicométrico indican que en la tabla $\mathrm{N}^{\circ} 4$, todos los ítems alcanzan correlaciones ítem-test corregidas, que son estadísticamente significativas a una probabilidad menor de .05 y además que la confiabilidad asciende a 0.79 , resultados que indican que la escala tiene validez y confiabilidad.
Tabla № 4

Validez y confiabilidad de la escala de apreciación del estrés sociolaboral

\begin{tabular}{|c|c|c|c|c|c|}
\hline Item & $M$ & $r_{i t}$ & Item & M & $r_{i t}$ \\
\hline 1 & 1.10 & $.20^{*}$ & 26 & 1.45 & .34 * \\
\hline 2 & 1.12 & .28 * & 27 & 1.78 & 28 * \\
\hline 3 & 1.14 & .29 * & 28 & 1.62 & .20 * \\
\hline 4 & 2.15 & $.26^{*}$ & 29 & 1.10 & .39 * \\
\hline 5 & 1.42 & $.44^{*}$ & 30 & 1.40 & .21 * \\
\hline 6 & 1.41 & $.27^{*}$ & 31 & 2.46 & .33 * \\
\hline 7 & 2.16 & $.55^{*}$ & 32 & 1.3 & 4.38 * \\
\hline 8 & 2.13 & .22 * & 33 & 2.2 & 5.22 * \\
\hline 9 & 2.15 & .31 * & 34 & 1.09 & .20 * \\
\hline 10 & 2.39 & $.24^{*}$ & 35 & 2.1 & 9.26 * \\
\hline 11 & 2.18 & .20 * & 36 & 1.48 & .33 * \\
\hline 12 & 2.31 & $.21^{*}$ & 37 & 2.33 & .20 * \\
\hline 13 & 2.10 & .32 * & 38 & 1.34 & .27 * \\
\hline 14 & 2.17 & $.20^{*}$ & 39 & 2.74 & .22 * \\
\hline 15 & 2.19 & .33 * & 40 & 1.50 & 35 * \\
\hline 16 & 2.12 & $.21^{*}$ & 41 & 1.51 & .38 * \\
\hline 17 & 2.71 & .32 * & 42 & 1.68 & .30 * \\
\hline 18 & 1.86 & $.20^{*}$ & 43 & 2.35 & .22 * \\
\hline 19 & 1.51 & .31 * & 44 & 2.24 & .21 * \\
\hline 20 & 1.45 & .32 * & 45 & 1.90 & .24 * \\
\hline 21 & 2.75 & $.20^{*}$ & 46 & 1.98. & 28 * \\
\hline 22 & 2.23 & $.41^{*}$ & 47 & 1.97 & .29 * \\
\hline 23 & 2.52 & $.27^{*}$ & 48 & 1.65 & .20 * \\
\hline 24 & 2.26 & .30 * & 49 & 1.80 & .22 * \\
\hline 25 & 2.21 & .23 * & 50 & 1.56 & .30 * \\
\hline
\end{tabular}

\section{Cuestionario de los cinco grandes factores - BFQ}

El BFQ (Big Five Questions) fue desarrollado por Caprara, Barbaranelli y Borgogni (1993), en la Organizzazioni Speciali (OS) de Florencia. La versión utilizada en el presente estudio corresponde a la adaptación realizada por Bermúdez en España (Caprara, Barbaranelli y Borgogni, 1995).

Este instrumento tiene por finalidad evaluar cinco dimensiones y diez sub- 
dimensiones de la personalidad y una escala de distorsión.

El BFQ ha sido concebido tomando en cuenta la preeminencia de la solución de cinco factores respecto de otras soluciones y toma en consideración la experiencia de McCrae y Costa; tiene por finalidad aportar algunas mejoras a la comprensión y evaluación de estos cinco factores. Este instrumento se ha propuesto:

- Ser más parsimoniosos en la identificación de las subdimensiones y en el número de elementos.

- Tomar en cuenta de forma escrupulosa las clasificaciones tradicionales de los cinco factores y de sus subdimensiones.

- Incorporar a la evaluación de los cinco factores una medida de la tendencia a dar una imagen "falseada" de sí mismo, mediante una escala de distorsión (D).

Los cinco grandes factores han sido denominados: energía, afabilidad, tesón, estabilidad emocional y apertura mental.

En cada uno de los Big Five se han identificado dos subdimensiones, cada una de las cuales hace referencia a distintos aspectos de la propia dimensión. En cada subdimensión (integrada por 12 elementos) la mitad de las afirmaciones han sido planteadas en sentido positivo con respecto al nombre de la escala, mientras la otra mitad está enunciada en sentido negativo, con el fin de controlar eventuales fenómenos de sesgos de respuesta.
La escala de distorsión (D) consta de 12 elementos y tiene por finalidad el proporcionar una medida de la tendencia a ofrecer un perfil falseado de sí mismo al responder al cuestionario.

En total, el BFQ consta de 182 elementos, y las dimensiones y subdimensiones evaluadas son:

- Energía (E). Definida de acuerdo con las siguientes subdimensiones:

- Dinamismo (Di). Mide los aspectos relativos a comportamientos enérgicos y dinámicos, la facilidad de palabra y el entusiasmo.

- Dominancia (Do). Que evalúa los aspectos relacionados con la capacidad de imponerse, sobresalir, hacer valer la propia influencia sobre los demás.

- Afabilidad (A). Se define por las siguientes subdimensiones:

- Cooperación/empatía (Cp). Mide los aspectos asociados a la capacidad para comprender y hacerse eco de los problemas y necesidades de los demás y cooperar eficazmente con ellos.

- Cordialidad/amabilidad (Co). Mide los aspectos relacionados con afabilidad, confianza y apertura hacia los demás.

- Tesón (T). Incluye las siguientes subdimensiones:

- Escrupulosidad (Es). Mide los aspectos relativos a fiabilidad, meticulosidad y amor por el orden. 
- Perseverancia (Pe). Mide aspectos que se refieren a la persistencia y tenacidad con que se llevan a cabo las tareas y actividades emprendidas y el no faltar a lo prometido.

- Estabilidad emocional (EE). Conformada por las siguientes subdimensiones:

- Control de las emociones (Ce). Mide básicamente aspectos concernientes al control de los estados de tensión asociados a la experiencia emotiva.

- Control de los impulsos (Ci). Mide aspectos relativos a la capacidad de mantener el control del propio comportamiento incluso en situaciones de incomodidad, conflicto y peligro.

- Apertura mental (AM). Viene definida por las siguientes subdimensiones:

- Apertura a la cultura (Ac). Mide los aspectos que corresponden al interés por mantenerse informados, interés hacia la lectura e interés por adquirir conocimientos.

- Apertura a la experiencia (Ae). Mide aspectos de la apertura mental: disposición favorable hacia novedades, capacidad de considerar cada cosa desde perspectivas diversas y apertura favorable hacia valores, estilos, modos de vida y culturas distintos.

- Escala de distorsión. Tiene por finalidad evaluar las distorsiones, so- bre todo por parte de sujetos motivados a dar de sí una imagen favorable o (en casos mucho más raros) desfavorable, que se presentan al contestar un cuestionario, debido a que se pueden tener distintas ideas sobre qué respuestas son admisibles y cuáles no, que pueden falsear significativamente (en sentido positivo o negativo) las respuestas.

Esta escala permite identificar la tendencia a alterar las respuestas con el propósito de ofrecer una falsa impresión de sí mismo, particularmente en todas aquellas situaciones en que se considere se pueda obtener alguna ventaja con ello.

No existe información sobre la utilización de este instrumento en nuestro medio, por lo que fue necesario evaluar su validez y confiabilidad. Los resultados del estudio de la validez de constructo a través de las correlaciones ítem-test (véase tablas $\mathrm{N}^{\circ} 5,6,7,8$ ), indica que en todas las dimensiones existen correlaciones estadísticamente significativas y además que el análisis factorial exploratorio (véase tabla $\mathrm{N}^{\circ}$ 9) corrobora la existencia de los cinco factores, lo que permite concluir que el cuestionario es válido.

El estudio de la confiabilidad a través del coeficiente alfa de Cronbach, mediante subdimensiones (véase tabla $\mathrm{N}^{\mathrm{o}}$ 10) y por factores (véase tabla $\mathrm{N}^{\circ} 11$ ), muestra coeficientes que son significativos, por lo que se concluye que el instrumento es confiable. 
Tabla № 5

Análisis de ítems de las subdimensiones de dinamismo, dominancia y cooperación del BFQ

\begin{tabular}{lll|lll|lll}
\hline & \multicolumn{3}{c|}{ Dinamismo } & \multicolumn{3}{c|}{ Dominancia } & \multicolumn{3}{c}{ Cooperación } \\
Item & $\mathbf{M}$ & $\mathbf{r}_{\text {it }}$ & Item & $\mathbf{M}$ & $\mathbf{r}_{\text {it }}$ & Item & $\mathbf{M}$ & $\mathbf{r}_{\text {it }}$ \\
\hline 1 & 4.51 & $.20^{*}$ & 13 & 2.47 & $.18^{*}$ & 4 & 4.15 & $.19^{*}$ \\
7 & 3.99 & $.28^{*}$ & 19 & 4.17 & $.33^{*}$ & 10 & 3.95 & $.22^{*}$ \\
25 & 2.54 & $.30^{*}$ & 31 & 4.22 & $.37^{*}$ & 28 & 3.96 & $.19^{*}$ \\
37 & 4.10 & $.29^{*}$ & 39 & 4.32 & $.42^{*}$ & 34 & 3.97 & $.22^{*}$ \\
51 & 3.22 & $.27^{*}$ & 59 & 4.09 & $.40^{*}$ & 48 & 2.06 & $.22^{*}$ \\
53 & 3.15 & $.19^{*}$ & 61 & 3.40 & $.22^{*}$ & 64 & 3.04 & $.26^{*}$ \\
68 & 3.78 & $.21^{*}$ & 71 & 2.34 & $.19^{*}$ & 70 & 3.33 & $.21^{*}$ \\
78 & 3.74 & $.42^{*}$ & 73 & 4.20 & $.35^{*}$ & 86 & 4.10 & $.23^{*}$ \\
94 & 3.89 & $.43^{*}$ & 95 & 3.89 & $.29^{*}$ & 100 & 2.75 & $.29^{*}$ \\
99 & 3.43 & $.32^{*}$ & 102 & 4.08 & $.30^{*}$ & 109 & 3.38 & $.30^{*}$ \\
114 & 4.33 & $.29^{*}$ & 117 & 3.99 & $.27^{*}$ & 111 & 4.25 & $.24^{*}$ \\
121 & 2.99 & $.34^{*}$ & 123 & 3.65 & $.29^{*}$ & 130 & 4.05 & $.22^{*}$ \\
\hline
\end{tabular}

${ }^{*} \mathrm{p}<.05$

$\mathrm{N}=100$

Tabla № 6

Análisis de ítems de las subdimensiones de cordialidad, escrupulosidad y perseverancia del BFQ

\begin{tabular}{|c|c|c|c|c|c|c|c|c|}
\hline \multirow{2}{*}{$\begin{array}{l}\text { Cordialidad } \\
\text { Item }\end{array}$} & \multirow[b]{2}{*}{ M } & \multirow[b]{2}{*}{$r_{i t}$} & \multicolumn{3}{|c|}{ Escrupulosidad } & \multicolumn{3}{|c|}{ Perseverancia } \\
\hline & & & Item & M & $r_{\text {it }}$ & Item & M & $r_{i t}$ \\
\hline 16 & 4.34 & $.22^{*}$ & 2 & 3.58 & $.20^{*}$ & 14 & 2.25 & $.28^{*}$ \\
\hline 22 & 3.86 & $.19^{*}$ & 8 & 2.69 & $.24^{*}$ & 20 & 4.30 & $.29^{*}$ \\
\hline 40 & 2.52 & $.27^{*}$ & 26 & 3.34 & $.27^{*}$ & 46 & 3.45 & $.25^{\star}$ \\
\hline 44 & 3.82 & $.19^{*}$ & 32 & 3.25 & $.28^{*}$ & 48 & 2.14 & $.24^{*}$ \\
\hline 52 & 4.06 & $.24^{*}$ & 57 & 2.21 & $.35^{*}$ & 49 & 3.10 & $.35^{*}$ \\
\hline 65 & 3.71 & $.23^{*}$ & 66 & 3.15 & $.21^{*}$ & 54 & 4.36 & $.27^{\star}$ \\
\hline 74 & 2.83 & $.21^{*}$ & 79 & 2.36 & $.33^{*}$ & 75 & 2.97 & $.33^{*}$ \\
\hline 88 & 2.39 & $.23^{*}$ & 82 & 4.30 & $.24^{*}$ & 85 & 3.80 & $.42^{*}$ \\
\hline 93 & 4.45 & $.25^{\star}$ & 106 & 3.08 & $.38^{*}$ & 96 & 4.59 & $.54^{*}$ \\
\hline 108 & 2.86 & $.19^{*}$ & 110 & 2.91 & $.29^{*}$ & 107 & 4.64 & $.45^{\star}$ \\
\hline 126 & 3.12 & $.26^{*}$ & 129 & 4.23 & $.35^{\star}$ & 115 & 2.32 & $.30^{*}$ \\
\hline 128 & 2.60 & $.24^{*}$ & 132 & 2.12 & $.20^{*}$ & 125 & 4.50 & $.22^{*}$ \\
\hline
\end{tabular}


Tabla № 7

Análisis de ítems de las subdimensiones de control de emociones, control de impulsos y apertura cultural del BFQ

\begin{tabular}{|c|c|c|c|c|c|c|c|c|}
\hline \multicolumn{3}{|c|}{ Control de emociones } & \multicolumn{3}{|c|}{ Control de impulsos } & \multicolumn{3}{|c|}{ Apertura cultural } \\
\hline Ítem & M & $r_{\text {it }}$ & Ítem & M & $r_{i t}$ & Ítem & $\mathbf{M}$ & $r_{i t}$ \\
\hline 3 & 3.88 & $.20^{*}$ & 21 & 3.02 & $.25^{\star}$ & 5 & 3.25 & $.22^{\star}$ \\
\hline 9 & 3.32 & $.21^{*}$ & 25 & 3.14 & $.24^{*}$ & 11 & 3.42 & $.24^{\star}$ \\
\hline 27 & 3.45 & $.34^{*}$ & 43 & 3.15 & $.26^{*}$ & 29 & 3.12 & $.56^{\star}$ \\
\hline 33 & 4.76 & $.27^{\star}$ & 45 & 2.17 & $.27^{\star}$ & 42 & 2.65 & $.21^{*}$ \\
\hline 50 & 3.48 & $.38^{*}$ & 58 & 3.82 & $.28^{*}$ & 55 & 4.04 & $.20^{\star}$ \\
\hline 62 & 4.92 & $.23^{*}$ & 63 & 2.93 & $.20^{*}$ & 60 & 3.35 & $.24^{\star}$ \\
\hline 69 & 3.34 & $.35^{\star}$ & 76 & 4.46 & $.34^{*}$ & 77 & 2.72 & $.28^{\star}$ \\
\hline 81 & 2.56 & $.26^{*}$ & 83 & 2.52 & $.35^{\star}$ & 87 & 3.18 & $.27^{\star}$ \\
\hline 89 & 3.78 & $.25^{\star}$ & 91 & 3.19 & $.26^{*}$ & 90 & 4.39 & $.29^{\star}$ \\
\hline 98 & 4.35 & $.24^{*}$ & 104 & 4.30 & $.29^{*}$ & 105 & 3.22 & $.30^{\star}$ \\
\hline 122 & 3.12 & $.27^{\star}$ & 116 & 3.22 & $.22^{*}$ & 112 & 2.37 & $.54^{\star}$ \\
\hline 120 & 3.40 & $.28^{*}$ & 119 & 3.73 & $.23^{*}$ & 124 & 4.12 & $.33^{\star}$ \\
\hline
\end{tabular}

Tabla № 8

Análisis de ítems de la subdimensión de control de emociones y la escala de distorsión del BFQ

\begin{tabular}{lll|lll}
\hline \multicolumn{2}{l}{$\begin{array}{l}\text { Control de emociones } \\
\text { Ítem }\end{array}$} & $\mathbf{M}$ & $\mathbf{r}_{\mathrm{it}}$ & \multicolumn{3}{l}{ Control de impulsos } \\
\hline 17 & 2.24 & $.23^{*}$ & 6 & $\mathbf{M}$ & $\mathbf{r}_{\text {it }}$ \\
\hline 23 & 3.26 & $.24^{*}$ & 12 & 1.98 & $.46^{*}$ \\
35 & 4.28 & $.25^{*}$ & 18 & 2.98 & $.28^{*}$ \\
41 & 3.40 & $.21^{*}$ & 24 & 3.44 & $.48^{*}$ \\
47 & 2.13 & $.20^{*}$ & 30 & 3.69 & $.47^{*}$ \\
56 & 3.36 & $.28^{*}$ & 36 & 2.43 & $.41^{*}$ \\
67 & 4.37 & $.29^{*}$ & 80 & 2.92 & $.50^{*}$ \\
72 & 3.90 & $.31^{*}$ & 84 & 2.18 & $.49^{*}$ \\
94 & 2.21 & $.35^{*}$ & 92 & 2.37 & $.32^{*}$ \\
103 & 3.57 & $.45^{*}$ & 101 & 3.43 & $.51^{*}$ \\
118 & 3.44 & $.26^{*}$ & 113 & 2.17 & $.49^{*}$ \\
131 & 3.23 & $.27^{*}$ & 127 & 3.65 & $.28^{*}$ \\
\hline
\end{tabular}

${ }^{*} \mathrm{p}<.05$

$\mathrm{N}=100$ 
Tabla № 9

Análisis de ítems de la subdimensión de control de emociones y la escala de distorsión del BFQ

\begin{tabular}{llllll}
\hline Subdimensiones & Factor 1 & Factor 2 & Factor 3 & Factor 4 & Factor 5 \\
\hline Dinamismo & .78 & & & & \\
Dominancia & .73 & & & \\
Cooperación & & .85 & & \\
Cordialidad & & .74 & & .90 \\
Escrupulosidad & & & & .85 \\
Perseverancia & .85 & & & \\
Control de emociones & .87 & & .70 & \\
Control de impulsos & & & & .80 & \\
Apertura a la cultura & & & & & \\
Apertura a la experiencia & & $13.90 \%$ & $12.70 \%$ & $9.20 \%$ & $7.5 \%$ \\
\hline Varianza explicada & $37.50 \%$ & & & & \\
\hline
\end{tabular}

$\mathrm{N}=100$

Tabla № 10

Confiabilidad de las subdimensiones del BFQ

\begin{tabular}{lll}
\hline Subdimensiones & Coeficiente Alfa & F \\
\hline Dinamismo & .65 & $2.86^{*}$ \\
Dominancia & .67 & $3.03^{*}$ \\
Cooperación & .68 & $3.13^{*}$ \\
Cordialidad & .63 & $2.70^{*}$ \\
Escrupulosidad & .71 & $3.45^{*}$ \\
Perseverancia & .74 & $3.85^{*}$ \\
Control de emociones & .72 & $3.57^{*}$ \\
Control de impulsos & .73 & $3.70^{*}$ \\
Apertura a la cultura & .66 & $2.94^{*}$ \\
Apertura a la experiencia & .72 & $3.57^{*}$ \\
Distorsión & .76 & $4.17^{*}$ \\
\hline
\end{tabular}

${ }^{*} p<.05$

Tabla № 11

Confiabilidad de las subdimensiones del BFQ

\begin{tabular}{lll}
\hline Dimensiones & Coeficiente Alfa & F \\
\hline Energía & .79 & $4.76^{*}$ \\
Afabilidad & .73 & $3.70^{*}$ \\
Tesón & .70 & $3.33^{*}$ \\
Estabilidad emocional & .82 & $5.56^{*}$ \\
Apertura mental & .76 & $4.17^{*}$ \\
\hline
\end{tabular}

${ }^{*} p<.05$

$\mathrm{N}=100$ 


\section{Inventario de solución y} afrontamiento de problemas ISAP

El ISAP, fue desarrollado por Miguel y Casado (1992) con la finalidad de mejorar el PSI (Problem Solving Inventory) construido por Heppner y Petersen en 1982, quienes crearon un instrumento para medir la capacidad que poseen los sujetos para resolver sus problemas personales.

Para la construcción del instrumento, se utilizaron los mejores ítems del PSI, se reformularon algunos de ellos y se incluyeron nuevos elementos. En la primera fase los autores tradujeron el PSI, tratando de mantener el significado original. La aplicación piloto de la prueba arrojó los siguientes resultados:

- Se transformaron catorce ítems para hacerlos más comprensibles.

- En cinco ítems se invirtió el sentido de las frases pasando de ser frases negativas a positivas.

- En dos ítems más, se eliminó el vocablo 'no', aunque se mantuvo el sentido negativo de dichos elementos.

- Se eliminaron los ítems que implicaban frecuencia o cantidad.

- El ítem 8 fue reformulado.

El sistema de respuesta correspondió a una escala tipo Likert de frecuencias de cinco puntos. La versión final fue trabajada en base al análisis factorial exploratorio el cual denotó la existencia de los siguientes factores:
- El factor 1: Dimensión de confianza-inseguridad en sí mismo. Es un factor bipolar que está conformado por 12 ítems que reflejan aspectos tales como: confianza en la habilidad personal, seguridad, satisfacción por la propia capacidad, en un polo; y miedo a cometer errores, intranquilidad y dudas sobre la habilidad personal, en el otro polo.

- El factor II: Reflexividad-impulsividad. Es también un factor de carácter bipolar y está constituido por seis ítems que reflejan, por un lado. reflexión, toma de tiempo para meditar sobre la acción y sus consecuencias, etc.; por otro, refleja una conducta rápida e irreflexiva para tomar decisiones, inmediatez, apresuramiento.

- El factor III: Estrategias de resolución. Es de tipo unipolar y viene definido por siete ítems referidos a contenidos tales como búsqueda de información, evaluación de errores, análisis de las condiciones, búsqueda de alternativas de solución al problema, etc.

Como este inventario no ha sido trabajado aún en nuestro medio, fue necesario verificar su validez y confiabilidad; para ello, en la tabla $\mathrm{N}^{\circ} 12$, se encuentra que en las tres dimensiones, todas las correlaciones ítem-test corregidas son estadísticamente significativas y los coeficientes de confiabilidad son también consistentes, por lo que se concluye que el inventario es válido y confiable. 
Tabla № 12

Análisis de ítems de las subdimensiones de: confianza-seguridad, reflexividad-impulsividad y estrategias de resolución del ISAP

\begin{tabular}{|c|c|c|c|c|c|c|c|c|}
\hline \multicolumn{3}{|c|}{$\begin{array}{c}\text { Confianza-inseguridad en } \\
\text { sí mismo }\end{array}$} & \multicolumn{3}{|c|}{ Reflexividad-impulsividad } & \multicolumn{3}{|c|}{ Estrategias de resolución } \\
\hline Ítem & $\mathbf{M}$ & $r_{i t}$ & Ítem & M & $r_{\text {it }}$ & Ítem & $\mathbf{M}$ & $r_{\text {it }}$ \\
\hline 1 & 2.11 & $.27^{*}$ & 3 & 2.33 & .23 * & 5 & 2.23 & .40 * \\
\hline 2 & 2.10 & $.26 *$ & 8 & 2.45 & .34 * & 9 & 2.24 & .22 * \\
\hline 4 & 2.25 & .21 * & 11 & 2.75 & $.38 *$ & 13 & 2.82 & .50 * \\
\hline 6 & 3.26 & $.20^{*}$ & 12 & 2.89 & $.28^{*}$ & 14 & 2.35 & .51 * \\
\hline 7 & 2.37 & .25 * & 16 & 2.92 & .29 * & 17 & 2.36 & $.23^{*}$ \\
\hline 10 & 2.38 & .31 * & 20 & 2.50 & $.24^{*}$ & 18 & 2.10 & .24 * \\
\hline 15 & 2.33 & $.28^{*}$ & & & & 21 & 2.09 & $.28^{*}$ \\
\hline 19 & 2.50 & .29 * & & & & & & \\
\hline 22 & 3.10 & .34 * & & & & & & \\
\hline 23 & 2.22 & .36 * & & & & & & \\
\hline 24 & 3.34 & .51 * & & & & & & \\
\hline 25 & 2.26 & $.20^{*}$ & & & & & & \\
\hline \multicolumn{3}{|c|}{ Alfa $=0.88^{*}$} & \multicolumn{3}{|c|}{ Alfa $=0.70^{*}$} & \multicolumn{3}{|c|}{ Alfa $=0.79 *$} \\
\hline
\end{tabular}

\section{Escala de autovaloración del} desempeño laboral

Para el desarrollo del presente estudio fue necesario desarrollar una escala, la cual tuvo por finalidad evaluar la propia valoración del desempeño laboral que presentan los participantes. Para ello se utilizó un formato de escala gráfica conformada por diez indicadores referidos a las actividades que desarrollan en un determinado centro laboral y que intentaban indagar acerca de la forma como realizan sus actividades laborales, calificándolas en un sistema de seis puntos que van desde una valoración positiva hasta una valoración negativa.

Todos los ítems de la escala fueron construidos específicamente para el desarrollo de la presente investigación y los resultados del análisis de la validez y confiabilidad, presentados en la tabla $\mathrm{N}^{\circ}$ 13, permiten apreciar que los diez ítems alcanzan correlaciones ítem-test corregidos, estadísticamente significativas, además que el coeficiente alfa asciende a 0.79 , resultados que certifican la adecuación psicométrica del instrumento.

Tabla № 13

Análisis de la escala de percepción del rendimiento laboral

\begin{tabular}{lrl}
\hline Item & $\mathrm{M}$ & $\mathrm{r}_{\text {it }}$ \\
\hline 1 & 3.23 & $.22^{*}$ \\
2 & 3.48 & $.25^{*}$ \\
3 & 3.22 & $.26^{*}$ \\
4 & 4.56 & $.27^{*}$ \\
5 & 3.23 & $.28^{*}$ \\
6 & 3.79 & $.20^{*}$ \\
7 & 3.56 & $.21^{*}$ \\
8 & 3.49 & $.22{ }^{*}$ \\
9 & 3.84 & $.23^{*}$ \\
10 & 3.55 & $.33^{*}$ \\
\hline \multicolumn{3}{c}{$\mathrm{Plfa}=0.79$ * } \\
\end{tabular}




\section{Inventario de satisfacción laboral (IST)}

El inventario fue desarrollado por Smith, y adaptado en España por López (1982). Puede ser administrado tanto en forma individual como colectiva y el tiempo de aplicación es de aproximadamente 25 minutos. Tiene por finalidad evaluar el grado de satisfacción en relación con el trabajo, mandos intermedios, salario, compañeros y promoción.

En su versión original, este instrumento consideró, dentro de los factores situacionales, la estratificación según la prosperidad o decadencia del sector donde está situada la empresa. Esto es posible debido a las exhaustivas estadísticas, al complejo procesamiento de datos del censo y a la actividad económica que se realiza en ese país.

La elaboración del IST fue larga (aproximadamente 10 años) debido al gran número de variables personales y situacionales que considera. Como señala López, el marco teórico del IST corresponde a los planteamientos anteriormente señalados y es necesario tomarlo en cuenta debido a que en la actualidad existen discrepancias en torno al verdadero significado y a los determinantes de la satisfacción en el trabajo.

El inventario esta constituido por 18 ítems que aluden a diferentes aspectos valorativos acerca del objeto de evaluación, en su versión original incluye los siguientes rubros: director, trabajo actual, salario actual, oportunidades de ascender y compañeros.
Debido a que no existen reportes bibliográficos que indiquen la existencia de estudios con este instrumento en nuestro medio, fue necesario realizar el estudio de la validez y confiabilidad de la prueba en los aspectos relacionados con la actividad laboral, compañeros e ingresos económicos. Los resultados presentados en la tabla $\mathrm{N}^{\circ} 14$, indican que los ítems de cada uno de los aspectos son significativos debido a que alcanzan correlaciones ítem-test superiores al criterio establecido, en tanto que en la confiabilidad se aprecia que los coeficientes alfa de Cronbach son superiores a 0.70 , resultados que indican que el inventario es válido y confiable.

\section{Resultados}

Los resultados han sido organizados de acuerdo con el tipo de análisis realizado. En primer lugar se comparan los grupos de empleo único y pluriempleo y en segundo lugar se presenta el análisis de los perfiles de los grupos estudiados.

\section{Comparación de los grupos de empleo único y pluriempleo}

En la tabla $N^{\circ} 15$ se observa que en la comparación de las subdimensiones y factores no existen, en ningún caso, diferencias estadísticas significativas entre los grupos de empleo único y pluriempleo.

En lo que se refiere a las comparaciones, de acuerdo con los tipos de afron- 
Tabla № 14

Validez y confiabilidad del inventario de satisfacción laboral

\begin{tabular}{|c|c|c|c|c|c|c|c|c|}
\hline \multicolumn{3}{|c|}{ Actividad Laboral } & \multicolumn{3}{|c|}{ Compañeros } & \multicolumn{3}{|c|}{ Ingresos Económicos } \\
\hline Item & $\mathbf{M}$ & $r_{i t}$ & Item & $\mathbf{M}$ & $r_{i t}$ & Item & $\mathbf{M}$ & $r_{i t}$ \\
\hline 1 & 0.50 & $.20^{*}$ & 1 & 0.42 & $.20^{\star}$ & 1 & 0.34 & $.22^{*}$ \\
\hline 2 & 0.53 & $.24^{*}$ & 2 & 0.50 & $.23^{*}$ & 2 & 0.65 & $.25^{*}$ \\
\hline 3 & 0.65 & $.25^{\star}$ & 3 & 0.43 & $.25^{\star}$ & 3 & 0.67 & $.24^{*}$ \\
\hline 4 & 0.57 & $.26^{\star}$ & 4 & 0.39 & $.29^{*}$ & 4 & 0.82 & $.28^{*}$ \\
\hline 5 & 0.60 & $.23^{*}$ & 5 & 0.27 & $.28^{\star}$ & 5 & 0.52 & $.26^{*}$ \\
\hline 6 & 0.62 & $.31^{*}$ & 6 & 0.47 & $.27^{\star}$ & 6 & 0.41 & $.23^{*}$ \\
\hline 7 & 0.64 & $.35^{\star}$ & 7 & 0.48 & $.26^{\star}$ & 7 & 0.52 & $.22^{*}$ \\
\hline 8 & 0.51 & $.35^{\star}$ & 8 & 0.45 & $.53^{*}$ & 8 & 0.63 & $.33^{*}$ \\
\hline 9 & 0.42 & $.20^{*}$ & 9 & 0.60 & $.34^{*}$ & 9 & 0.54 & $.20^{\star}$ \\
\hline 10 & 0.52 & $.26^{\star}$ & 10 & 0.89 & $.21^{*}$ & 10 & 0.59 & $.34^{*}$ \\
\hline 11 & 0.82 & $.28^{\star}$ & 11 & 0.81 & $.20^{\star}$ & 11 & 0.27 & $.33^{*}$ \\
\hline 12 & 0.63 & $.27^{\star}$ & 12 & 0.86 & $.36^{\star}$ & 12 & 0.18 & $.61^{*}$ \\
\hline 13 & 0.90 & $.29^{\star}$ & 13 & 0.74 & $.34^{*}$ & 13 & 0.56 & $.25^{\star}$ \\
\hline 14 & 0.45 & $.31^{*}$ & 14 & 0.75 & $.38^{*}$ & 14 & 0.34 & $.28^{*}$ \\
\hline 15 & 0.60 & $.40^{*}$ & 15 & 0.93 & $.51^{*}$ & 15 & 0.57 & $.21^{*}$ \\
\hline 16 & 0.75 & $.30^{*}$ & 16 & 0.60 & $.26^{\star}$ & 16 & 0.62 & $.23^{*}$ \\
\hline 17 & 0.42 & $.29^{\star}$ & 17 & 0.54 & $.33^{*}$ & 17 & 0.60 & $.28^{*}$ \\
\hline 18 & 0.55 & $.24^{\star}$ & 18 & 0.40 & $.34^{*}$ & 18 & 0.45 & $.20^{*}$ \\
\hline \multicolumn{3}{|c|}{ Alfa $=0.76$} & \multicolumn{3}{|c|}{ Alfa $=0.80$} & \multicolumn{3}{|c|}{ Alfa $=0.83$} \\
\hline
\end{tabular}

Tabla № 15

Análisis comparativo entre grupos de estudio de las subdimensiones y factores del BFQ

\begin{tabular}{|c|c|c|c|c|c|c|}
\hline \multirow{3}{*}{ Variable } & \multicolumn{4}{|c|}{ Grupo } & \multirow{3}{*}{ t. } & \multirow{3}{*}{$\begin{array}{l}\text { Sig. a } \\
2 \text { colas }\end{array}$} \\
\hline & \multicolumn{2}{|c|}{$\begin{array}{l}\text { Empleo Unico } \\
\qquad N=50\end{array}$} & \multicolumn{2}{|c|}{$\begin{array}{l}\text { Pluriempleo } \\
\qquad \mathrm{N}=50\end{array}$} & & \\
\hline & $\mathbf{M}$ & D.E. & M & D.E. & & \\
\hline \multicolumn{7}{|c|}{ Sub-dimensiones } \\
\hline Dinamismo & 43.54 & 4.33 & 43.08 & 5.46 & 0.47 & .642 \\
\hline Dominancia & 43.72 & 4.65 & 43.84 & 4.95 & -0.12 & .901 \\
\hline Cooperación & 43.24 & 3.95 & 43.10 & 3.91 & 0.18 & .857 \\
\hline Cordialidad & 41.44 & 4.34 & 40.18 & 4.64 & 1.40 & .164 \\
\hline Escrupulosidad & 41.58 & 4.98 & 42.14 & 4.06 & -0.62 & .539 \\
\hline Perseverancia & 46.38 & 4.21 & 46.90 & 5.04 & -0.56 & .577 \\
\hline Control de emociones & 42.66 & 6.01 & 41.56 & 5.87 & 0.93 & .356 \\
\hline Control de impulsos & 39.72 & 5.56 & 38.34 & 6.30 & 1.16 & .248 \\
\hline Apertura cultural & 43.96 & 5.15 & 44.40 & 5.36 & -0.42 & .677 \\
\hline Apertura a la experiencia & 45.40 & 5.03 & 45.10 & 5.17 & 0.29 & .769 \\
\hline \multirow[t]{2}{*}{ Escala de distorsión } & 31.10 & 1.22 & 21.14 & 1.21 & -0.16 & .870 \\
\hline & \multicolumn{4}{|c|}{ Factores } & & \\
\hline Energía & 87.26 & 7.79 & 86.92 & 9.02 & 0.20 & .840 \\
\hline Afabilidad & 84.68 & 7.13 & 83.28 & 7.27 & 0.97 & .333 \\
\hline Tesón & 87.96 & 6.89 & 89.04 & 4.14 & -0.77 & .444 \\
\hline
\end{tabular}


tamiento según grupo de estudio presentados en la tabla $\mathrm{N}^{\circ} 16$, se puede observar que sólo existen diferencias significativas favorables al grupo de pluriempleo $(\mathrm{M}=9.20, \mathrm{DE}=2.56)$ en la búsqueda de apoyo social por razones instrumentales $(\mathrm{t}(98)=-2.51, \mathrm{p}$ $<.05)$. En tanto que en la comparación de los estilos de afrontamiento que predominan entre los grupos estudiados, no se aprecian diferencias estadísticas significativas en ningún caso.

Con respecto al contraste del patrón de conducta tipo A, en la tabla $\mathrm{N}^{\circ} 17$ notamos que los miembros del grupo de pluriempleo alcanzan valores significativos más elevados $(M=123.70$, $\mathrm{DE}=7.13)$ que los del grupo de empleo único $(\mathrm{M}=102.28, \mathrm{DE}=7.41)$. En la comparación del estrés sociolaboral se aprecia que el grupo con pluriempleo $(\mathrm{M}=31.06, \mathrm{DE}=2.48)$ presenta significativamente mayor cantidad de acontecimientos estresantes que el grupo de empleo único $(\mathrm{M}=18.52$, $\mathrm{DE}=2.48)$, resultado que también se repite en el caso de la intensidad del estrés.

Tabla № 16

Análisis comparativo entre grupos de estudio de los tipos y estilos de afrontamiento de Carver

\begin{tabular}{|c|c|c|c|c|c|c|}
\hline \multirow{4}{*}{ Variable } & \multicolumn{4}{|c|}{ Grupo } & \multirow{4}{*}{ t. } & \multirow{4}{*}{$\begin{array}{l}\text { Sig. a } \\
2 \text { colas }\end{array}$} \\
\hline & \multirow{2}{*}{\multicolumn{2}{|c|}{$\begin{array}{l}\text { Empleo único } \\
\qquad N=50\end{array}$}} & \multirow{2}{*}{\multicolumn{2}{|c|}{$\begin{array}{l}\text { Pluriempleo } \\
\qquad \mathrm{N}=50\end{array}$}} & & \\
\hline & & & & & & \\
\hline & $\mathbf{M}$ & D.E. & $\mathbf{M}$ & D.E. & & \\
\hline & \multicolumn{4}{|c|}{ Tipo de afrontamiento } & & \\
\hline Afrontamiento Activo & 10.75 & 2.79 & 10.61 & 2.41 & 0.26 & .799 \\
\hline Planificación & 11.30 & 2.54 & 11.20 & 2.53 & 0.20 & .844 \\
\hline Supresión de Actividades Competentes & 10.56 & 2.86 & 10.46 & 3.69 & 0.15 & .880 \\
\hline Postergación del Afrontamiento & 9.96 & 3.33 & 10.44 & 3.66 & -0.69 & .494 \\
\hline $\begin{array}{l}\text { Búsqueda de Apoyo Social por } \\
\text { razones instrumentales }\end{array}$ & \multicolumn{5}{|c|}{ razones instrumentales } & $.014^{*}$ \\
\hline \multicolumn{6}{|l|}{ razones emocionales } & .075 \\
\hline Reinterpretación Positiva & 8.86 & 3.83 & 7.86 & 3.55 & 1.36 & .178 \\
\hline Aceptación & 9.06 & 2.75 & 9.46 & 2.84 & -0.71 & .476 \\
\hline Negación & 9.64 & 2.61 & 9.40 & 2.51 & 0.47 & .641 \\
\hline Acudir a la religión & 11.94 & 2.71 & 11.60 & 2.38 & 0.67 & .507 \\
\hline Enfocar y liberar emociones & 6.94 & 2.30 & 6.38 & 2.18 & 1.25 & .215 \\
\hline Desentendimiento conductual & 6.26 & 1.83 & 6.28 & 2.30 & -0.05 & .962 \\
\hline \multirow[t]{2}{*}{ Desentendimiento mental } & 5.96 & 1.62 & 6.13 & 1.49 & -0.58 & .564 \\
\hline & \multicolumn{4}{|c|}{ Estilo de afrontamiento } & & \\
\hline Enfocado hacia el problema & 50.51 & 7.78 & 51.91 & 8.14 & -0.88 & .382 \\
\hline
\end{tabular}


Tabla № 17

Análisis comparativo entre grupos de estudio del patrón de conducta tipo A, estrés sociolaboral y solución y afrontamiento de problemas

\begin{tabular}{|c|c|c|c|c|c|c|}
\hline \multirow{4}{*}{ Variable } & \multicolumn{4}{|c|}{ G r u po } & \multirow{4}{*}{ t. } & \multirow{4}{*}{$\begin{array}{l}\text { Sig. a } \\
2 \text { colas }\end{array}$} \\
\hline & \multirow{2}{*}{\multicolumn{2}{|c|}{$\begin{array}{l}\text { Empleo único } \\
\qquad N=50\end{array}$}} & \multirow{2}{*}{\multicolumn{2}{|c|}{$\begin{array}{l}\text { Pluriempleo } \\
\qquad \mathrm{N}=50\end{array}$}} & & \\
\hline & & & & & & \\
\hline & $\mathbf{M}$ & D.E. & $\mathbf{M}$ & \multirow[t]{2}{*}{ D.E. } & & \\
\hline & & trón de & ucta tipo & & & \\
\hline \multirow[t]{2}{*}{ Conducta tipo A } & 102.28 & 7.41 & 123.70 & 7.13 & -14.72 & $.000^{*}$ \\
\hline & \multicolumn{4}{|c|}{ Estrés socio-laboral } & & \\
\hline Acontecimientos estresantes & 18.52 & 2.48 & 31.06 & 5.61 & -14.45 & $.000^{*}$ \\
\hline \multirow[t]{2}{*}{ Intensidad del estrés } & 60.76 & 10.07 & 88.86 & 11.71 & -12.86 & $.000^{*}$ \\
\hline & \multicolumn{4}{|c|}{ Solución y afrontamiento de problemas } & & \\
\hline Confianza - inseguridad en sí mismo & 25.12 & 3.79 & 23.86 & 3.10 & 1.82 & .072 \\
\hline Reflexividad - impulsividad & 17.16 & 5.97 & 15.60 & 5.90 & 1.31 & .192 \\
\hline Estrategia de resolución & 19.66 & 4.88 & 18.62 & 5.90 & 0.96 & .339 \\
\hline $\begin{array}{l}\text { Solución y afrontamiento de } \\
\text { problemas total }\end{array}$ & 61.94 & 14.10 & 58.08 & 14.88 & 1.33 & .186 \\
\hline
\end{tabular}

En lo que concierne a la solución y afrontamiento de problemas, se encuentra que los grupos de empleo único y pluriempleo alcanzan resultados similares tanto en las áreas de confianzainseguridad en sí mismo, reflexividadimpulsividad, estrategia de resolución y la solución y afrontamiento de problemas total.

El análisis de la satisfacción laboral, (véase tabla $\mathrm{N}^{\circ} 18$ ), permite notar la presencia de diferencias estadísticas significativas en favor del grupo de empleo único en lo que se refiere a la satisfacción con las actividades laborales $(\mathrm{M}=39.72, \mathrm{DE}=6.65)$ y la satis- facción con los compañeros $(\mathrm{M}=$ $40.00, \mathrm{DE}=6.95$ ), en tanto que el grupo de pluriempleo los supera en la satisfacción con los ingresos económicos $(\mathrm{M}=42.98, \mathrm{DE}=6.64)$.

En el caso de la autovaloración del desempeño laboral, se encuentra que los profesionales pertenecientes al grupo de empleo único manifiestan de forma significativa una mejor autovaloración de su desempeño laboral $(\mathrm{M}=$ $27.48, \mathrm{DE}=4.08)$ que el grupo de pluriempleo $(\mathrm{M}=23.66, \mathrm{DE}=3.44)$. 
Tabla № 18

Análisis comparativo entre grupos de estudio de la satisfacción laboral

\begin{tabular}{|c|c|c|c|c|c|c|}
\hline \multirow{3}{*}{ Variable } & \multicolumn{4}{|c|}{ G rupo } & \multirow{3}{*}{ t. } & \multirow{3}{*}{$\begin{array}{l}\text { Sig. a } \\
2 \text { colas }\end{array}$} \\
\hline & \multicolumn{2}{|c|}{$\begin{array}{l}\text { Empleo Unico } \\
\qquad N=50\end{array}$} & \multicolumn{2}{|c|}{$\begin{array}{c}\text { Pluriempleo } \\
\mathrm{N}=50\end{array}$} & & \\
\hline & $\mathbf{M}$ & D.E. & M & D.E. & & \\
\hline & \multicolumn{4}{|c|}{ Satisfacción Laboral } & & \\
\hline $\begin{array}{l}\text { Satisfacción en actividades } \\
\text { laborales }\end{array}$ & 39.72 & 6.65 & 36.00 & 5.75 & 2.99 & $.004^{*}$ \\
\hline Satisfacción con los compañeros & 40.00 & 6.95 & 33.00 & 6.25 & 5.30 & $.000^{*}$ \\
\hline \multirow[t]{2}{*}{ económicos } & 38.64 & 5.99 & 42.98 & 6.64 & -3.43 & $.001^{*}$ \\
\hline & \multicolumn{5}{|c|}{ Autovaloración del Desempeño Laboral } & \\
\hline Desempeño Laboral & 27.48 & 4.08 & 23.66 & 3.44 & 5.06 & $.000^{*}$ \\
\hline
\end{tabular}

\section{Comparación de perfiles según grupo} de estudio

Con la finalidad de evaluar la presencia de diferentes perfiles en los grupos estudiados, se desarrolló el análisis discriminante, que es presentado en la tabla $\mathrm{N}^{\circ} 19$, en la cual se puede observar que sólo ocho de todas las variables estudiadas diferencian de manera significativa los grupos de profesionales. Estas variables corresponden a los as- pectos vinculados al estrés (acontecimientos estresantes, solución y afrontamiento de problemas), la satisfacción laboral (ingresos económicos, actividades laborales y compañeros), el patrón de conducta tipo A, y el factor de personalidad de energía. Estas variables forman una sola función discriminante que alcanza una elevada y significativa correlación canónica $(\mathrm{rc}=0.93, \mathrm{WL}=$ $0.14, \quad X 2(8)=184.04, \mathrm{p}<.05)$.

Tabla № 19

Análisis discriminante según grupos de estudio

\begin{tabular}{lcc}
\hline Variable & Wilks Lambda & Función canónica \\
\hline Patrón de conducta tipo A & 0.31 & 0.67 \\
Acontecimientos estresantes & 0.22 & 0.45 \\
Solución y afrontamiento de problemas & 0.21 & 0.43 \\
Intensidad total del estrés & 0.18 & 0.41 \\
Satisfacción con ingresos económicos & 0.17 & 0.64 \\
Satisfacción con actividades laborales & 0.16 & 0.76 \\
Satisfacción con los compañeros & 0.15 & 0.42 \\
Factor de energía & 0.14 & 0.26 \\
\hline
\end{tabular}

Correlación canónica $=0.93$

Wilks's Lambda $=0.14$

Chi-cuadrado $=184.04$ 
El análisis de la representación de los resultados, presentado en el gráfico $\mathrm{N}^{\mathrm{o}}$ 1 , permite observar que los centroides de los dos grupos de empleo único y pluriempleo están distanciados entre sí en más de cuatro puntos, lo que lleva a que en ambas distribuciones no existan casos que se superpongan.

Para establecer la eficacia de los resultados del análisis discriminante, se efectuó el análisis de la tabulación cruzada de los sujetos clasificados sobre la base de la función discriminante y el grupo original al que pertenecen. En la tabla $\mathrm{N}^{\mathrm{o}} 20$ se aprecia que la diferenciación se da en el $100 \%$ de los casos, lo que indica que ambos perfiles son totalmente diferenciados.

\section{Tabla № 20}

Tabulación cruzada entre el grupo actual y el grupo predicho

\begin{tabular}{cccc}
\hline Grupo actual & Casos & $\begin{array}{c}\text { Grupo predicho } \\
\text { Empleo } \\
\text { único }\end{array}$ & $\begin{array}{c}\text { Pluri- } \\
\text { empleo }\end{array}$ \\
\hline Empleo único & 50 & 50 & 0 \\
& & $100.00 \%$ & $0.00 \%$ \\
Pluriempleo & 50 & 0 & 50 \\
& & $0.00 \%$ & $100.00 \%$ \\
\hline
\end{tabular}

Porcentaje de casos agrupados correctamente $=100.00 \%$

\section{Gráfico № 1}

Distribución en la función discriminante de los grupos estudiados

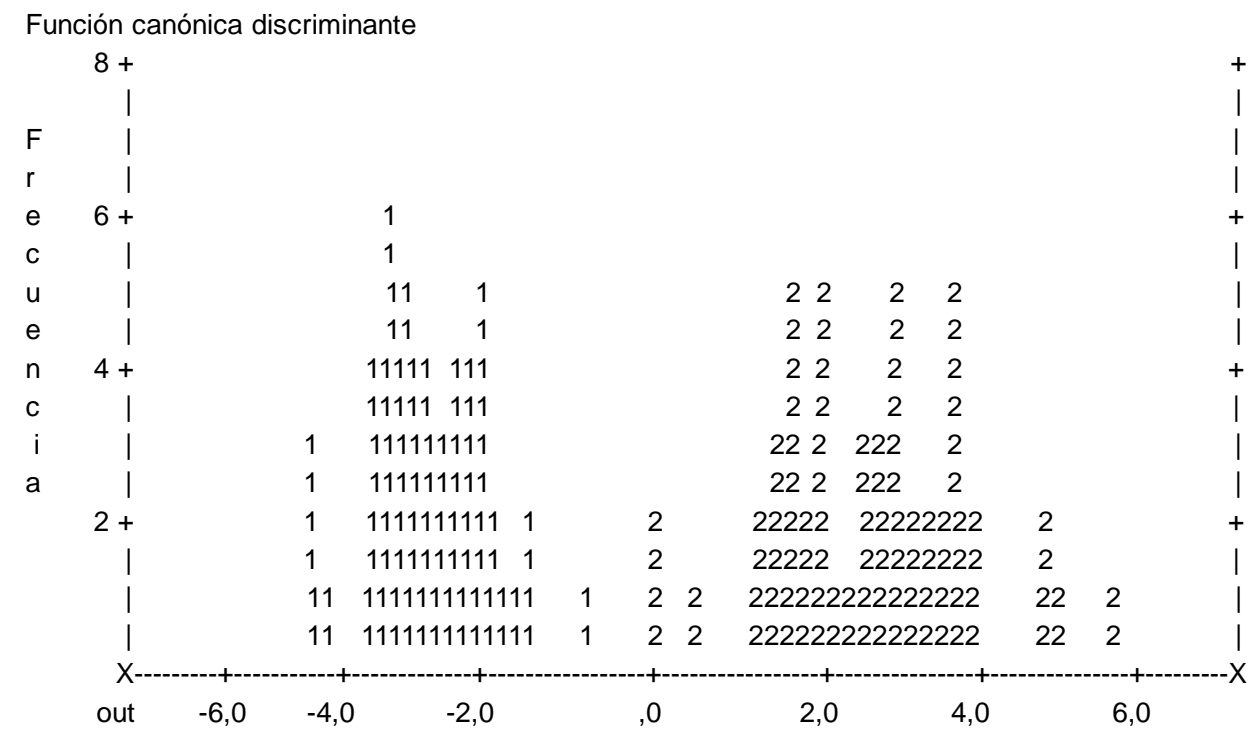

Clases $\quad 11111111111111111111111111111111111111122222222222222222222222222222222222222$ Centroides 


\section{Discusión}

La investigación realizada ha implicado la revisión de numerosas variables, las cuales han sido exploradas tanto en trabajadores con empleo único como pluriempleados. Esta cantidad de variables se justifica debido a los escasos conocimientos existentes en nuestro medio sobre el tema tratado. Los resultados obtenidos serán analizados desde dos perspectivas, la primera que corresponde a los instrumentos de medición y la segunda a los hallazgos obtenidos en comparaciones de los trabajadores.

Con relación a los instrumentos aplicados, el inventario de autorreporte de conducta tipo A de Blumenthal al presentar validez y confiabilidad, concuerda con los hallazgos del estudio de León, Romero y Sirlopú (1995) en estudiantes universitarios, lo cual podría ser considerado como una forma de validación cruzada (Anastasi y Urbina, 1998), lo que sirve de evidencia para demostrar la relevancia de dicho constructo en nuestro contexto.

Los hallazgos favorables obtenidos en el análisis de los componentes de la prueba de afrontamiento Cope de Carver, sirven para corroborar lo adecuado que es dicho instrumento para ser utilizado en la investigación psicológica en nuestro medio, pues sus resultados son equivalentes a los alcanzados por $\mathrm{Ca}$ suso (1996), de manera que se puede apreciar la vigencia actual de la prueba.
Respecto del estudio de la escala de apreciación del estrés sociolaboral, aplicado en nuestro contexto por primera vez en la presente investigación, también ha demostrado ser útil para evaluar el estrés en el ámbito laboral, facilitando la calificación de los distintos acontecimientos en la vida de los participantes, de manera que permite conocer el número de acontecimientos estresantes que han estado presentes, a la vez que apreciar la intensidad con que cada uno vive o ha vivido esos sucesos vitales.

La concepción de la teoría de los cinco grandes factores de la personalidad (Big Factor) evaluado a través del $\mathrm{BFQ}$, ha sido corroborada por los resultados obtenidos de forma empírica en el estudio psicométrico, pues tanto los ítems como las dimensiones han probado ser válidos y confiables. Además, el estudio factorial exploratorio ha permitido verificar la existencia de los cinco factores de la personalidad propuestos por McCrae y Costa (energía, afabilidad, tesón, estabilidad emocional y apertura mental), tal y como ha ocurrido en estudios previos desarrollados en otros contextos, tal como reportan Caprara, Barbaranelli y Borgogni (1995), lo que permitiría apoyar la universalidad de dicha concepción teórica acerca de la personalidad.

En lo que concierne a la solución y afrontamiento de problemas (ISAP), los resultados del estudio psicométrico 
han servido para confirmar los hallazgos de Miguel y Casado (1992). Encontrándose además que los factores originalmente encontrados (dimensión de confianza-inseguridad en sí mismo, reflexividad-impulsividad y estrategias de resolución) son comprobados por los resultados obtenidos en el análisis factorial desarrollado en el estudio.

La escala de autovaloración del desempeño laboral, construida especialmente para el desarrollo de la presente investigación también ha reportado tener validez y confiabilidad, hallazgo que nos permitirá contar en futuras investigaciones con un instrumento relevante para desarrollar estudios similares en el campo de la psicología laboral.

Con respecto al análisis del inventario de satisfacción sociolaboral (IST), desarrollado por Smith, y adaptado en España por López (1982), los resultados del análisis psicométrico han servido para ratificar de forma empírica su validez y confiabilidad, de modo que ha sido un instrumento útil para obtener resultados relevantes y, por lo tanto, es factible de ser trabajado en nuestro medio.

En términos generales, los resultados alcanzados por los diferentes instrumentos utilizados en el desarrollo de la presente investigación han servido para demostrar su calidad psicométrica, debido a esto han garantizado que los resultados de la investigación son producto de las características de los constructos medidos y no por el efecto aleatorio de otras variables.
En lo que concierne a los resultados encontrados en las comparaciones de las variables por tipo de empleo, se ha podido observar que a nivel del estudio de los cinco factores de la personalidad, aquellos trabajadores que se desempeñan en actividades múltiples no se diferencian de aquéllos que tienen un empleo único. Este hallazgo nos estaría indicando que los factores de personalidad constituyen rasgos estables de los sujetos, por lo que la preeminencia de alguno de ellos en algún tipo de trabajador estudiado, no sería un resultado consistente, sino que más bien sería algo aleatorio, pues la personalidad no estaría afectada por los sucesos del medio ambiente que estuvieran asociados a cierto tipo de actividad laboral y, por lo tanto, podría concluirse que en el desarrollo del pluriempleo podrían intervenir otro tipo de variables, especialmente de índole socioeconómica y no el tipo de personalidad.

En el caso del afrontamiento es interesante notar que los resultados indican la existencia de diferencias significativas en la mayor búsqueda de apoyo social por razones instrumentales en los trabajadores pluriempleados, es decir que estos trabajadores utilizan como forma constante de tratar de solucionar los problemas que se le presentan, el solicitar la ayuda de los diferentes miembros de su entorno. Lo cual nos lleva a pensar que debido a la gran cantidad de trabajo que deben desarrollar, no les es posible realizarlas sin la ayu- 
da de los demás, por lo tanto, el solicitar la ayuda de los demás es una opción aceptable. Este hallazgo es corroborado tanto por los resultados alcanzados en la mayor cantidad de situaciones problemáticas que deben enfrentar, tal como lo indica el elevado estrés sociolaboral que presentan y que les impediría tratar de solucionarlas de forma directa o individual; así como por los resultados del análisis del estrés sociolaboral en el cual presentan también una gran cantidad de acontecimientos estresantes, los cuales son percibidos como de mayor intensidad.

Con respecto al patrón de conducta tipo A, notamos que se encuentra mayormente elevado en los universitarios profesionales pluriempleados, por lo cual es factible que presenten la tendencia a mayores disposiciones comportamentales hacia la ambición, la agresividad, la competitividad e impaciencia; tensión muscular, ritmo acelerado de actividades, así como irritabilidad y hostilidad, lo que podría llevar -a la larga- a una predisposición a sufrir enfermedades coronarias debido al intenso trabajo que deben desplegar en la ejecución de sus actividades laborales. Este aspecto podría ser interesante para estudios posteriores, tomando en cuenta la posible presencia de conductas que sean factores de riesgo para ese tipo de enfermedades.

En el nivel de satisfacción laboral, resulta necesario indicar que los profesionales universitarios pluriempleados no están satisfechos con su actividad laboral ni con sus compañeros, estos hallazgos probablemente pueden deberse a la rotación constante que deben realizar en las diferentes instituciones en las cuales laboran, y que puede llevarlos a tener un contacto superficial con sus ocasionales compañeros y, por lo tanto, no lleguen a desarrollar una adecuada identificación con las instituciones en las que se desempeñan, cosa que no ocurre en el caso de los que cuentan con empleo único. Aunque resulta necesario indicar que los pluriempleados exhiben una mayor satisfacción en el aspecto económico, lo cual es de esperarse, pues el dinero podría considerarse como una recompensa con un agregado valor psicológico, debido a los esfuerzos desplegados para conseguirlo.

En lo que corresponde al desempeño laboral, encontramos que los trabajadores de empleo único obtienen una mayor calificación que los pluriempleados, lo cual podría deberse a que mientras los primeros tienen que concentrarse en el desarrollo de sus actividades de forma coordinada, los pluriempleados, por el contrario, se ven obligados a dispersarse e incluso a desarrollar diferentes roles de acuerdo con los diferentes contextos en los que laboran.

Finalmente, los resultados observados a nivel estadístico inferencial, trabajando con cada una de las variables estudiadas, han sido corroborados a un nivel estadístico multivariado, pues los hallazgos del análisis discriminante 
han permitido configurar de forma aún preliminar un perfil más integral del profesional universitario pluriempleado, el cual se caracterizaría por un elevado patrón de conducta tipo A, enfrentamiento a una mayor cantidad de acontecimientos estresantes, elevados niveles de intensidad total del estrés, alta satisfacción con los ingresos económicos, moderados niveles de energía y baja satisfacción con las actividades laborales y con los compañeros.

En conclusión, los hallazgos alcanzados que pueden ser considerados como preliminares debido a la naturaleza del estudio, nos han permitido identificar al profesional universitario pluriempleado que debe realizar un mayor esfuerzo físico, intelectual, emocional y adaptativo, que estaría desarrollando un perfil característico, el cual, pensamos, deberá ser ampliado, corroborado o modificado en posteriores investigaciones.

\section{REFERENCIAS}

Anastasi, A. \& Urbina, S. (1998). Tests psicológicos. México: Prentice Hall.

Blanch, J.M. (1997). Psicología social del trabajo. En J.L. Alvaro, A. Garrido \& J. R. Torregrosa (Eds.), Psicología social aplicada. Madrid: McGraw-Hill.

Borges del Rosal, A., Barbero, I., Maciá, A. \& Pérez Llantada, M.C. (1997). Análisis de contenido del constructo “madurez”. Iberpsicología, 2(1.2), 1-9.

Caprara, G. V., Barbaranelli, C. \& Borgogni, L. (1993). The Big Five questionnaire: A new questionnaire to asses the five factor model. Personality and Individual Difference, 15, 281-288.

Caprara, G. V., Barbaranelli, C. \& Borgogni, L. (1995). BFQ Cuestionario Big Five. Madrid: TEA S.A.

Carver, C. S. \& Scheier, M-F. (1989). Assessing coping strategies: A theoretically based approach. Journal of Personality and Social Psychology, 56, 267283.

Casuso, L. (1996). Adaptación de la prueba Cope sobre estilos de afrontamiento en grupos de estudiantes universitarios de Lima. Tesis de licenciatura no publicada, Pontificia Universidad Católica del Perú, Lima.

Colom, R. B. (1995). Tests, inteligencia y personalidad. Madrid: Ediciones Pirámide S.A.

Chiavenato, I. (1996). Administración de recursos humanos. México: McGrawHill.

Endler, N. S. \& Parker, J. D. (1990). Multidimensional assesment of coping: A critical evaluation. Journal of Person- 
ality Process and Individual Difference, 58, 844-854.

Fernández, J. L. \& Mielgo M. (1996). EAE, escala de apreciación del estrés. Madrid: TEA S.A.

Friedman, M. \& Rosenmam, R. H. (1959). Association of a specific overt pattern with increases in blood cholesterol, blood clotting time, incidence of arcus senilis and clinical coronary artery disease. Journal of the American Medical Association, 169, 1286-1296.

Golblaum, M. (1998). Life style and modernity, assessment of social policy reforms. Research in Latin America and the Caribbean: tendencies and challenges. New York: Free Press.

Hernández, L. (1997). Propiedades de la escala de Framingham para la medida del patrón de conducta tipo A y su relación con las variables ansiedad y locus de control. Iberpsicología, 1(1.1), 1-19.

Holmes, T. H. \& Rahe, R. H. (1967). The social readjustement rating scale. Journal of Psychosomatic Research, 11, 213-218.

Ivanicevich, J. M. \& Matteson, M. T. (1992). Estrés y trabajo: una perspectiva gerencial. México: De Trillas.

Jerusalem, M. (1993). Environmental constraints, and adaptational processes: The predictive power or a theoretical stress model. Personality and Individual Differences, 14(1), 15-24.

Kalimo, R. (1988). Los factores psicosociales en el trabajo. Ginebra: Organización Mundial de la Salud.

Kline, P. (1993). The handbook of psychological testing. London: Routhledge.
Laak T. J. (1996). Las cinco dimensiones de personalidad. Revista de Psicología, 14(2), 129-182.

Lazarus, R. S. (1966). Psychological stress and the coping process. Nueva York: McGraw-Hill.

Lazarus, R. S. (1996). Emotion and adaptation. Nueva York: Oxford University Press.

Lawler, E.E. \& Porter, L. (1973). Antecedentt attitudes of effective managerial performance. En V. H. Vroom. Management and motivation. Middlesex: Penguin Books.

León, R., Romero, C. \& Sirlopú D. (1995) Validación del inventario de autorreporte de conducta tipo A de Blumenthal et al. Revista de Neuro-Psiquiatría, 58, 20-36.

León, R., \& Sirlopú D. (1996). Diferencias de género en el patrón de conducta tipo A en un grupo de estudiantes universitarios de Lima Metropolitana. Revista de Psicología, 14(2), 183-210 .

López, L. (1982). Inventario de satisfacción laboral. Barcelona: Permat.

Loret de Mola, M. (1987). Patrón de conducta tipo A y frustración en un grupo de pacientes con enfermedades coronarias. Tesis de bachiller no publicada, Pontificia Universidad Católica del Perú, Lima.

Martínez Arias, R. (1996). Psicometría: Teoría de los tests psicológicos y educativos. Madrid: Editorial Síntesis.

Miguel, J. J. \& Casado, M. I. (1992 ). Solución de problemas personales: elaboración y desarrollo del inventario de solución y afrontamiento de problemas - 
ISAP. Investigaciones Psicológicas, 11, 137-152.

Muñiz, J. (1994). Teoría clásica de los tests. Madrid: Ed. Pirámide.

Muñiz, J. (1996). Psicometría. Madrid: Ed. Universitas S. A.

Organización Internacional del Trabajo. (1993). El trabajo en el mundo. Ginebra: OIT.

Pittner, M. S., Houston, B. K. \& Spiridigliozzi, G. (1983). Control over stress, type A behaviour pattern, and response to stress. Journal of Personality and Social Psychology, 44, 627-637.

Robbin, D (1995). Comportamiento organizacional. México: Prentice Hall.

Robles, H., Pérez, N., Reyes, G. \& Fernández Figares, R. (1997). Indicadores psicológicos y psicofisiológicos de riesgo coronario: un estudio transversal en pacientes cardíacos. Iberpsicología, 2 (2.5), 1-17.

Schwarzer, R. \& Hahn, A. (1995). Reemployment after migration from East to West Germany. Berlín: Free University of Berlín.

Slipak, O. (1996). Estrés laboral. Alcmeón, 1(4), 355-360.

Thoits, P. (1994). Stressors and problem solving: The individual as psychological activist. Journal of Health and Social Behavior, 35(2), 143-160.

Webb R. \& Fernández Baca, G. (1998). Perú 97 en números. Anuario estadístico. Lima: Cuánto S.A. 